\title{
Modeling the blockchain readiness challenges for product recovery system
}

\author{
Ashish Dwivedi ${ }^{1} \cdot$ Dindayal Agrawal $^{2}$ - Sanjoy Kumar Paul ${ }^{3}$ (D) Saurabh Pratap ${ }^{4}$
}

Accepted: 23 November 2021

(c) The Author(s), under exclusive licence to Springer Science+Business Media, LLC, part of Springer Nature 2021

\begin{abstract}
Product Recovery System (PRS) transfers products from their typical final place to their source to arrest some value on the product. There are obstructions, such as costs, associated with the modification of accounts and assessment of products and refunds associated with the implementation of PRS. Blockchain Technology (BCT) emerged as an innovative approach to constructing trust in a trust less environment and assures the availability, traceability, and security in data management. It also presents a valuable solution to PRS. This study aims to analyze the Blockchain Readiness Challenges (BRCs) to PRS in the context of manufacturing industries. The study observes 20 readiness challenges linked with the implementation of BCT in PRS. The BRCs are identified from the literature survey and confirmed after consequent examinations with industry experts and researchers. The study employed a Multi-Criteria Decision-Making (MCDM) i.e., the Decision-Making Trial And Evaluation Laboratory (Fuzzy DEMATEL) approach to find the cause-and-effect interactions to prioritize BRCs. The Maximum Mean De-Entropy (MMDE) algorithm was adopted to establish the threshold value based on the information entropy of the interactions among the BRCs for PRS. The fuzzy set theory was adopted to tackle the uncertainty and vagueness of personnel biases and data deficiency problems. The findings from this study reveal that inadequate financing for PRS exercises, lack of governance and standards, and security challenges to BCT implementation are the most influential readiness challenges for the adoption of blockchain in PRS. The study is useful to manufacturing organizations for identifying the potential BRCs to implement PRS among all existing readiness challenges so that they
\end{abstract}

$\bowtie$ Sanjoy Kumar Paul

sanjoy.paul@uts.edu.au

Ashish Dwivedi

ashish0852@gmail.com

Dindayal Agrawal

ddagrawal123@gmail.com

Saurabh Pratap

s.pratapiitkgp@gmail.com

1 Jindal Global Business School, O.P. Jindal Global University, Sonipat, India

2 Department of Management Studies, Indian Institute of Technology, Delhi, India

3 UTS Business School, University of Technology Sydney, Sydney, Australia

4 Department of Mechanical Engineering, Indian Institute of Technology (IIT BHU), Varanasi, India 
can take suitable measures before proceeding to adopt blockchain in PRS. The managers are suggested to eliminate the readiness challenges and widen the blockchain technology adoption in PRS.

Keywords Readiness challenges · Blockchain technology · Product recovery system · Multi-criteria decision-making · Fuzzy DEMATEL

\section{Introduction}

In the past decade, product recovery system (PRS), comprised of the movement of a product from the customer to the manufacturer by increasing additional movements in the revenue from customers and recycling and reprocessing consumed products, has acquired more consideration among researchers and society (Dwivedi \& Madaan, 2020). In some countries, there are laws and regulations to accumulate the used products by their manufacturers. Further, PRS benefits organizations to attain financial profits through used products and recycled/remanufactured parts. In the era of digitalization, several innovative technologies are executed in the PRS to trace the movement of products between the arbitrators in the supply network (Akter et al., 2020; Kouhizadeh \& Sarkis, 2018). Additionally, Internet of Things (IoT) sensors are embedded in products to maintain the tracking of parts in the product and store information regarding their condition (Alqahtani et al., 2019). It provides systematic product management both at the product and component level. The amalgamation of information, decision-making, and digital technologies in PRS result in a digitalized PRS. However, the technologies executed in the PRS are centralized and monitored by a dominant central authority (O'Dair and Beaven, 2017). This approach of the dominant central authority leads to trust issues, such as tampering, corruption, and fraud.

The BCT is adopted to enhance business in products and components, including marketing, buying, selling, planning, control, visibility, traceability, and reliability (Patil et al., 2020; Rezaee, 2019). BCT protects data by sharing business information, sustaining business interactions, and organizing business negotiations (Kamble et al., 2019; Zheng et al., 2020). Further, BCT contributes to increased efficiency, control, and facilitating commercial transactions (Luo \& Choi, 2021). BCT enhances product recovery planning and decision-making by eradicating the ambiguity specific to the valuable life of returned products (Tozanli et al., 2020). This efficiency makes the BCT more essential for enterprises due to its stability in providing a tighter control structure while enhancing transparency (Hungud et al., 2020). In PRS, a series of blockchain-digitization concerns are evident across the different stages of product movement, such as collection, separation, inspection, storage, and disassembly (Bekrar et al., 2021). The measures concerning security, traceability, and transparency can play an essential part in catering to blockchain-digitization concerns. Thus, it becomes necessary to identify the BRCs in the successful implementation of PRS.

Therefore, this paper contributes towards both the existing literature and an existing frame of convenient knowledge with the following objectives:

(a) To investigate the potential BRCs for PRS in the Indian manufacturing industry;

(b) To investigate the cause-and-effect relations among the identified potential BRCs for PRS adopting the fuzzy DEMATEL-MMDE methodology;

(c) To prioritize the identified potential BRCs for PRS and recommend managerial and practical implications. 
Previous literature has been examined to identify potential BRCs for PRS in the Indian manufacturing industry to attain the above-highlighted objectives. Several brainstorming sessions were organized with the industry managers from the Indian manufacturing industry to confirm the potential BRCs for PRS. Further, BRCs for PRS were evaluated and prioritized, adopting the fuzzy DEMATEL-MMDE approach.

The remaining paper is presented as follows. In Sect. 2, the literature review provides an overview of previous literature specific to blockchains, digital technologies, and PRS. The research methodology and the fuzzy DEMATEL-MMDE methodology are highlighted in Sect. 3. The results and discussion are presented in Sect. 4. Managerial implications are provided in Sect. 5. Finally, conclusions and future research directions are presented in Sect. 6.

\section{Literature review}

In this section, the previous literature relevant to the problem is considered. In this deference, the previous studies specific to product recovery, blockchains, barriers and challenges to product recovery, and applications of digital technologies are highlighted. Table 1 provides a summary of previous studies in the area of PRS.

\subsection{Recent literature on blockchain-based PRS}

Present business and industry prospects have been transforming promptly, involving flexible and efficient PRSs to cater to current confrontations in sustainability. Blockchains refer to disruptive technologies for the design, coordination, movement, and management of the supply chains (Saberi et al., 2019). This section highlights the previous studies specific to blockchain technology and how it is application-specific to Sustainable Supply Chains (SSC), Closed-Loop Supply Chains (CLCS), and PRSs. Gautam et al. (2021) studied product recovery and focussed on 3R's i.e., Reduce, Reuse and Recycle products, to reduce the waste. The developed model aims to minimize energy consumption and carbon gas emission during production, shortage of products, transportation, and disposal of defective products. Sarker et al. (2009) investigated to determine the Economic Order Quantity (EOQ) and product quantity to satisfy the customer demand by the combination of new products, recovered-used products.

Kouhizadeh et al. (2021) practiced the force field theory to identify barriers to blockchain adoption. The results from the study reflect that supply chain and technological barriers are the most critical barriers for adopting BCT to manage SSCs. Zhi et al. (2021) studied the investors concerning various risk criteria in investment decision-making through blockchain information. Further, Liu et al. (2021) proposed an environmental, social, and governance reporting framework based on blockchains to facilitate the sustainability evaluation of the listed companies. The results from the study contributed towards facilitating the sustainability-level evaluation of the organizations. Further, Tozanli et al. (2020) presented the employment of IoT rooted products in a blockchain facilitated disassembly-to-order system. The study adopted a discrete event simulation model to calculate the system's expected cost. Similarly, Esmaeilian et al. (2020) summarized blockchains and Industry 4.0 for attaining sustainability in supply chains. The study discussed the four capabilities of BCT towards a sustainable supply chain. Katsaliaki et al. (2021) studied and determined the challenges for supply chain disruption. The content analysis described the type of disruption and its influence on supply chain network design. 
Table 1 Analysis of the existing literature in the present domain

\begin{tabular}{|c|c|c|c|c|}
\hline Reference & Research problem & $\begin{array}{l}\text { Approach of the } \\
\text { study }\end{array}$ & $\begin{array}{l}\text { Context of the } \\
\text { study }\end{array}$ & $\begin{array}{l}\text { Considered } \\
\text { blockchain? } \\
\text { (Yes or No) }\end{array}$ \\
\hline Pan et al. (2015) & $\begin{array}{l}\text { Production } \\
\text { planning and } \\
\text { inventory control } \\
\text { for PRS }\end{array}$ & $\begin{array}{l}\text { Dynamic } \\
\text { programming } \\
\text { approach }\end{array}$ & General context & No \\
\hline $\begin{array}{l}\text { Sharma et al. } \\
\text { (2016) }\end{array}$ & $\begin{array}{l}\text { Benchmarking PRS } \\
\text { alternatives in } \\
\text { reverse logistics }\end{array}$ & $\begin{array}{l}\text { Superiority and } \\
\text { inferiority ranking } \\
\text { (SIR) method }\end{array}$ & $\begin{array}{l}\text { Manufacturing } \\
\text { industry }\end{array}$ & No \\
\hline $\begin{array}{l}\text { Fortuna and } \\
\text { Diyamandoglu } \\
(2017)\end{array}$ & $\begin{array}{l}\text { Optimizing of } \\
\text { GHG emissions } \\
\text { in PRS through } \\
\text { reuse platforms }\end{array}$ & Optimization model & $\begin{array}{l}\text { Manufacturing } \\
\text { industry }\end{array}$ & No \\
\hline $\begin{array}{l}\text { Marconi et al. } \\
\text { (2017) }\end{array}$ & $\begin{array}{l}\text { Traceability of } \\
\text { products and } \\
\text { investigate } \\
\text { sustainable } \\
\text { factors during } \\
\text { supply chain }\end{array}$ & Qualitative analysis & $\begin{array}{l}\text { Leather Shoe } \\
\text { industry }\end{array}$ & No \\
\hline $\begin{array}{l}\text { Marshall and } \\
\text { Archibald (2018) }\end{array}$ & $\begin{array}{l}\text { Product recovery } \\
\text { system within an } \\
\text { infinite planning } \\
\text { horizon, for } \\
\text { multiple } \\
\text { fixed-sized } \\
\text { productions }\end{array}$ & $\begin{array}{l}\text { An EOQ lot-sizing } \\
\text { model }\end{array}$ & $\begin{array}{l}\text { Manufacturing } \\
\text { industries }\end{array}$ & No \\
\hline $\begin{array}{l}\text { Kazancoglu et al. } \\
\text { (2018) }\end{array}$ & $\begin{array}{l}\text { Performance } \\
\text { assessment in } \\
\text { GSCM, which } \\
\text { combines } \\
\text { environmental, } \\
\text { economics, } \\
\text { logistics, } \\
\text { operational, } \\
\text { organizational }\end{array}$ & Fuzzy DEMATEL & Cement industry & No \\
\hline $\begin{array}{l}\text { De Oliveira et al. } \\
\text { (2019) }\end{array}$ & $\begin{array}{l}\text { Brazilian expanded } \\
\text { polystyrene } \\
\text { supply chain with } \\
\text { circular economy }\end{array}$ & Qualitative analysis & $\begin{array}{l}\text { Polystyrene } \\
\text { industry }\end{array}$ & No \\
\hline $\begin{array}{l}\text { Dwivedi et al. } \\
\text { (2020) }\end{array}$ & $\begin{array}{l}\text { Identification of } \\
\text { factors to } \\
\text { implement PRS } \\
\text { for circular } \\
\text { economy }\end{array}$ & Fuzzy VIKOR & $\begin{array}{l}\text { Manufacturing } \\
\text { industries }\end{array}$ & No \\
\hline $\begin{array}{l}\text { Gautam et al. } \\
(2021)\end{array}$ & $\begin{array}{l}\text { Product recovery } \\
\text { management } \\
\text { towards a cleaner } \\
\text { system }\end{array}$ & $\begin{array}{l}\text { Mathematical } \\
\text { model and } \\
\text { analysis }\end{array}$ & General context & No \\
\hline This study & $\begin{array}{l}\text { Analyze the BRCs } \\
\text { to PRS in the } \\
\text { context of } \\
\text { manufacturing } \\
\text { industries }\end{array}$ & Fuzzy DEMATEL & $\begin{array}{l}\text { Manufacturing } \\
\text { industries }\end{array}$ & Yes \\
\hline
\end{tabular}


Further, Varriale et al. (2020) conducted a literature review to illustrate the sustainable attributes of adopting BCT in supply chains. The study reflected the use of blockchains to improve profits for organizations. Choi et al. (2020) identified the factors that hinder organizations from merging BCT with the supply chain. The study adopted a partial least square approach for attaining the results. Vafadarnikjoo et al. (2021) analyzed the blockchain barriers for the manufacturing supply chain industry. The results identified the major barriers to implementing the supply chain network design. Shoaib et al. (2020) identified the success factors for implementing a blockchain-based supply chain. The accessibility and overall efficiency were identified as the highest-ranked success factors for blockchain implementation. Further, Paliwal et al. (2020) investigated the role of BCT in managing sustainable practices. The results from the study demonstrated traceability and transparency as the potential advantages of adopting BCT. Similarly, Ebinger and Omondi (2020) presented an overview of the digitalization of SSC transparency in SSC management. Bai and Sarkis (2020) introduced BCT performance measures integrating SSC transparency and technical attributes. The study can assist the managers and researchers in understanding the BCT selection decision.

Further, Manupati et al. (2020) developed a distributed ledger-based blockchain approach to examine supply chain performance and optimize emission levels and operational costs. The problem was formulated as a Mixed-Integer Non-Linear Programming (MINLP) model. Caldarelli et al. (2020) evaluated the effectiveness of blockchain technology for sustainability issues. The study addressed the blockchain oracle problem in the traceability of non-fungible products. Further, Sunmola (2021) presented a study of BCT concerning sustainable supply chain visibility. The study suggested a framework for blockchain-based sustainable supply chain visibility management, focusing on awareness of the context. Sahoo and Halder (2020) proposed a novel smart e-waste management system by adopting BCT and smart contracts, considering forward and reverse supply chains. The study discussed various challenges and limitations that existing blockchain solutions have been facing in e-waste management.

Similarly, Zhang et al. (2020) suggested a framework obtained from the integration of BCT, IoT, big data analytics, and visualization. The study can assist organizations in attaining operational excellence in organizing Life Cycle Assessments (LCA) for improving supply chain sustainability. Further, Yadav and Singh (2020) identified blockchain critical success factors in SSCs. The study integrated the concept of blockchain-related information technology and supply chain for operations. Rejeb and Rejeb (2020) performed a literature analysis to determine the studies specific to blockchain and supply chain sustainability. The results from the study concluded that the majority of studies focused on the economic implications of blockchains on supply chains. Sundarakani et al. (2021) studied a supply chain problem associated to cross border cargo transportation. Blockchains and big data were used to identify the key implementation guidelines and major issues faced during the supply chain network design. Marshall and Archibald (2018) investigated a problem related to PRS and proposed two recovery channels (i) recovery into components and (ii) into serviceable items. The study determined the total cost per unit period and optimal lot size.

Further, Mubarik et al. (2020) examined the role of blockchain-based sustainability on supply chain integration. The findings from the study revealed that blockchain technology has substantial capability to enhance the integration between numerous actors in multi-level supply chains. Similarly, Dindarian and Chakravarthy (2019) explored cases involving blockchain technology in the waste management industry. Parung (2019) highlighted the use of blockchain technology to support studies specific to SSCs. Further, Saberi et al. (2019) examined BCT and smart contracts with potential supply chain management. The study introduced four blockchain technology adoption barriers: inter-organizational, intra-organizational, technical, and external barriers. Further, Nayak and Dhaigude (2019) 
proposed a conceptual model of SSC in small and medium enterprises adopting BCT. The study identified the antecedents of an SSC using the BCT approach.

\subsection{Research gaps and contributions}

Based on deliberated literature study, it can be seen that a number of studies have examined barriers, challenges, and issues for a PRS's successful implementation. Additionally, there are numerous articles in the literature pertinent to blockchain-based architects. However, to the best of my knowledge, no study in the literature depicts their linkage with the PRS. There is a requirement to obtain the BRCs for PRS. Therefore, the current research focuses on the above concern and enhances the latest literature by:

- Finalizing potential BRCs with the help of literature review and experts' recommendations.

- Evaluating BRCs for PRS to achieve the ranking and categorization in cause-effect group by using the fuzzy DEMATEL-MMDE approach.

\subsection{Identification of BRCs for PRS}

In developing countries, manufacturing industries search for innovative digital technologies to enhance their performance through efficient collaboration and coordination in the recovery chain (Farooq \& O'Brien, 2012). In recent years, the adoption of BCT has resulted in better visibility and transparency of transactions in the recovery chains (Pilkington, 2016). In the literature, there are various readiness challenges for the successful implementation of blockchain in PRSs. Therefore, it becomes essential to study the potential BRCs for PRS. In the present study, twenty potential BRCs for PRS in the manufacturing industry were identified through a literature study and experts' recommendations. The identified BRCs for PRS are presented in Table 2.

\section{Methodology and data analysis}

This section explains the DEMATEL approach and MMDE algorithm, which are implemented to perform the data analysis and identify the potential BRCs for PRS implementation. Figure 1 shows the research framework adopted for the study with the different steps.

\subsection{Questionnaire development and data collection}

In this study, a questionnaire was arranged to accelerate data collection for the DEMATEL analysis, arresting the experts' recommendations. The questionnaire provided a detailed description of each BRC specific to PRS implementation to support the experts (Appendix 1). A total of 17 experts from different manufacturing industries in India were elected for collecting data based on adopting convenience sampling. The experts were contacted via phone calls and the web. Later, seven experts were approved to contribute to the survey. The sample size highlights the target population which is low but presumed to be satisfactory as seen in the previous studies that adopted the fuzzy DEMATEL approach (Kazancoglu et al., 2018; Khan et al., 2019; Parmar \& Desai, 2020). A brief introduction of the experts and their organizations is presented in Table 3. 


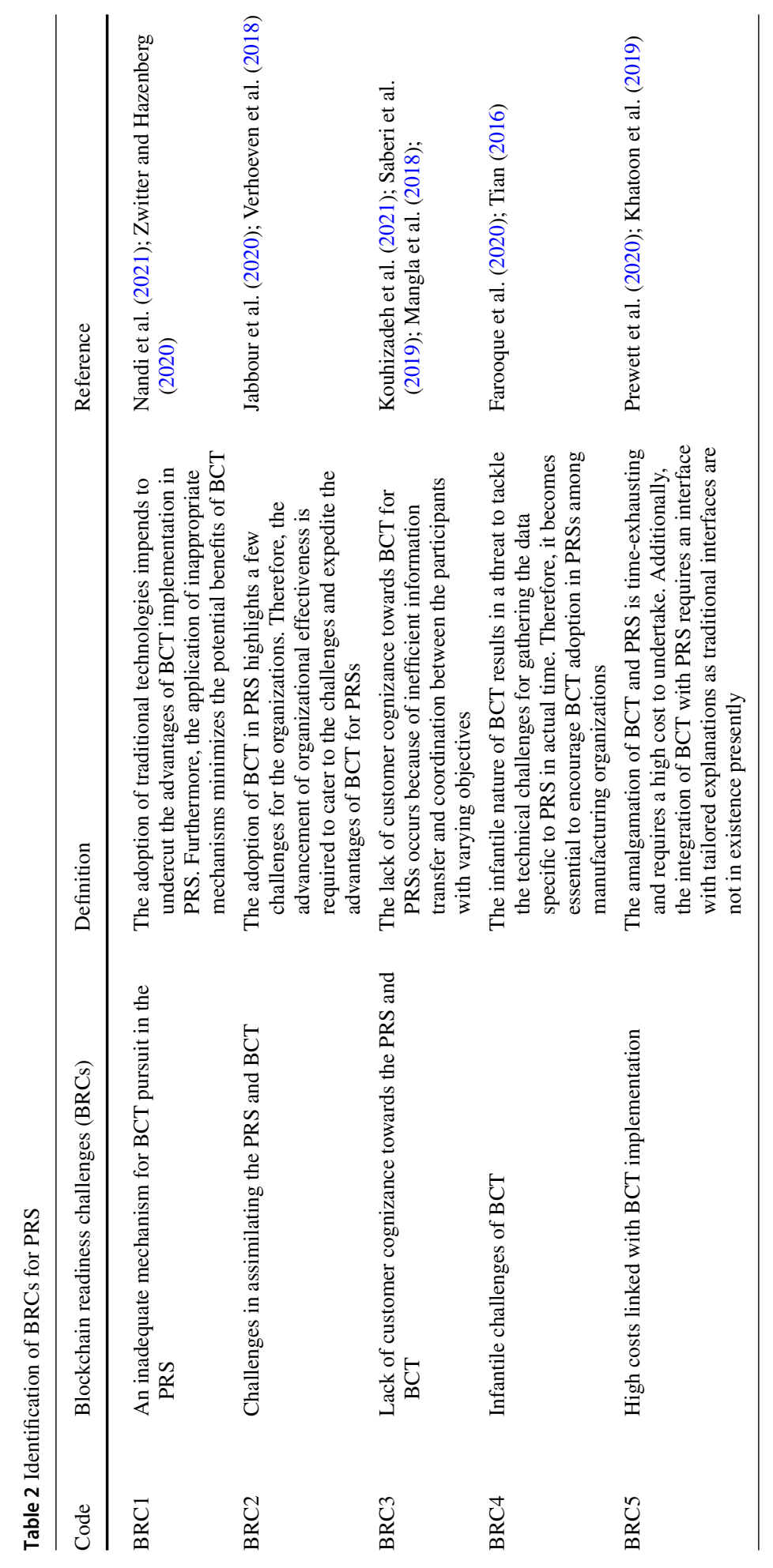




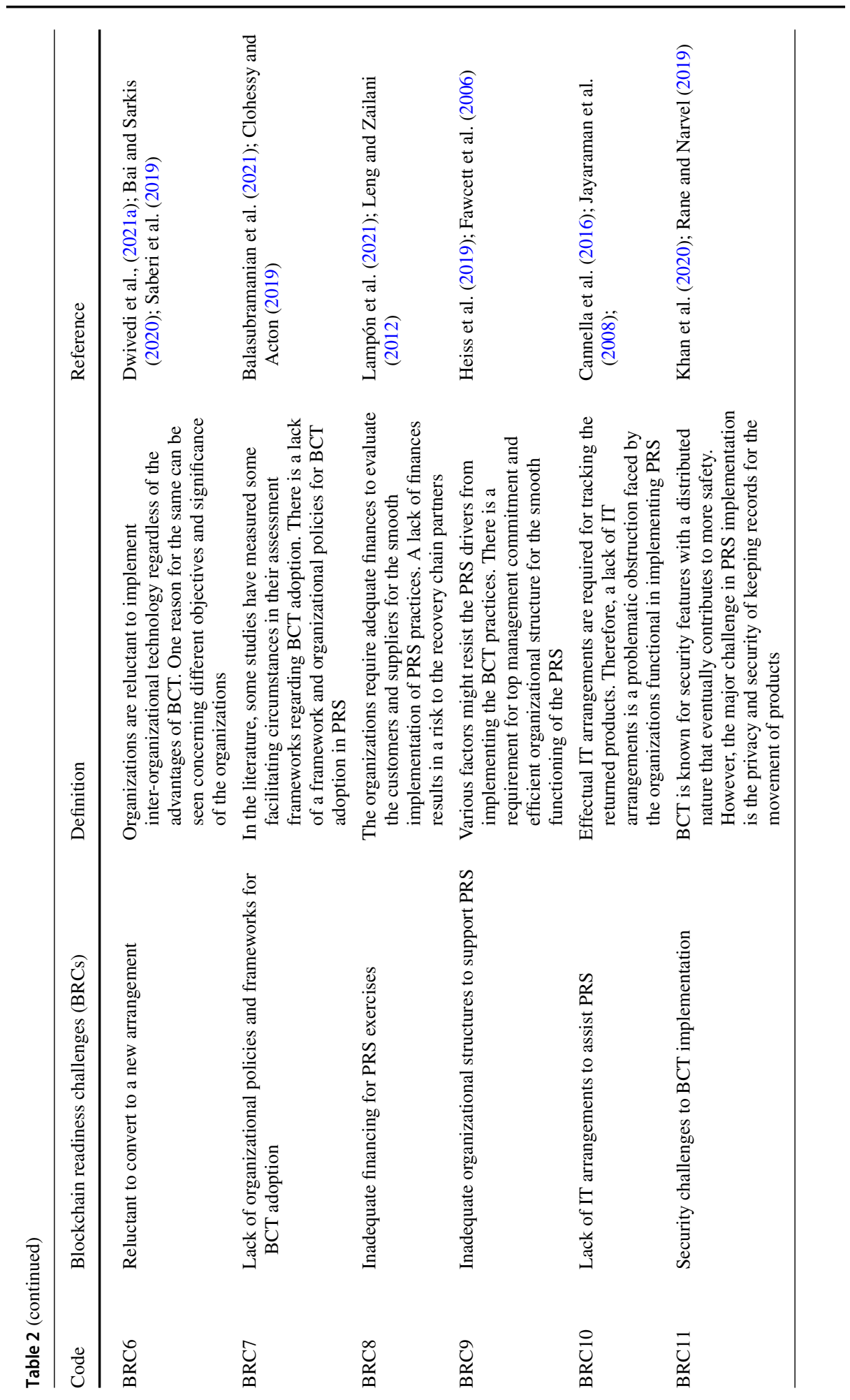




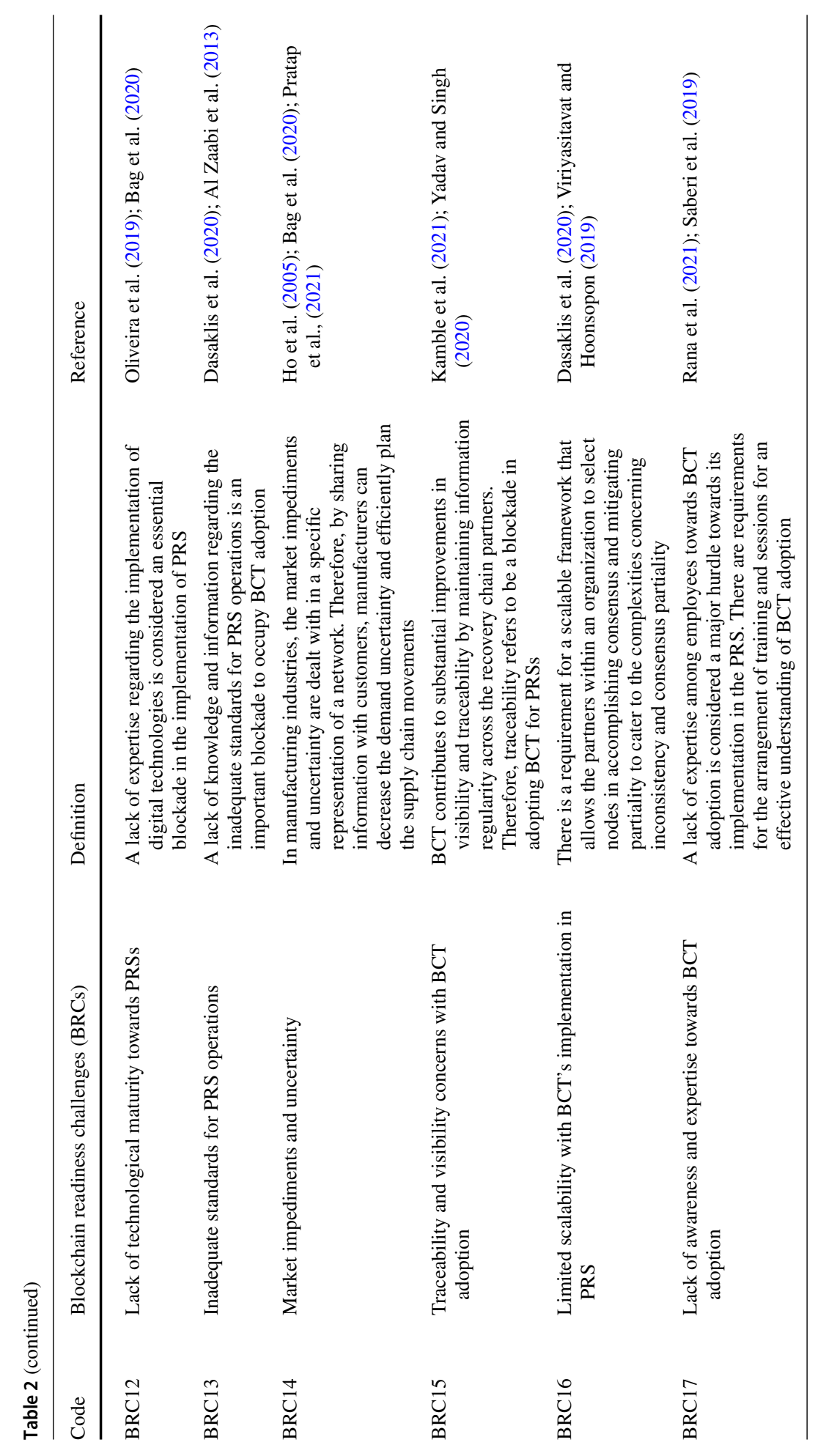




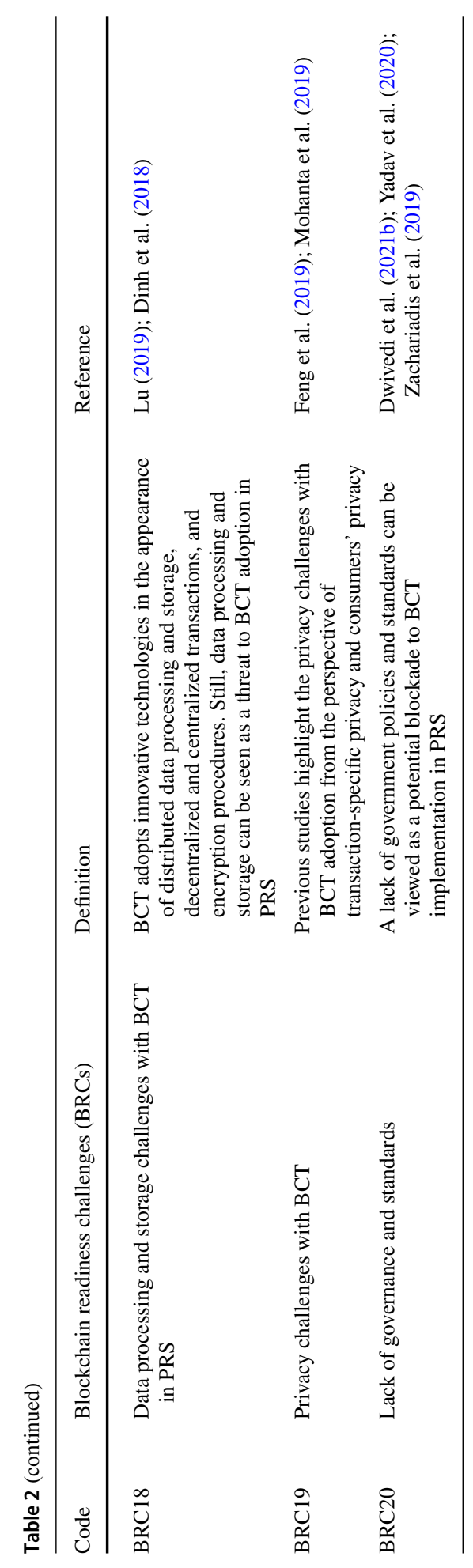




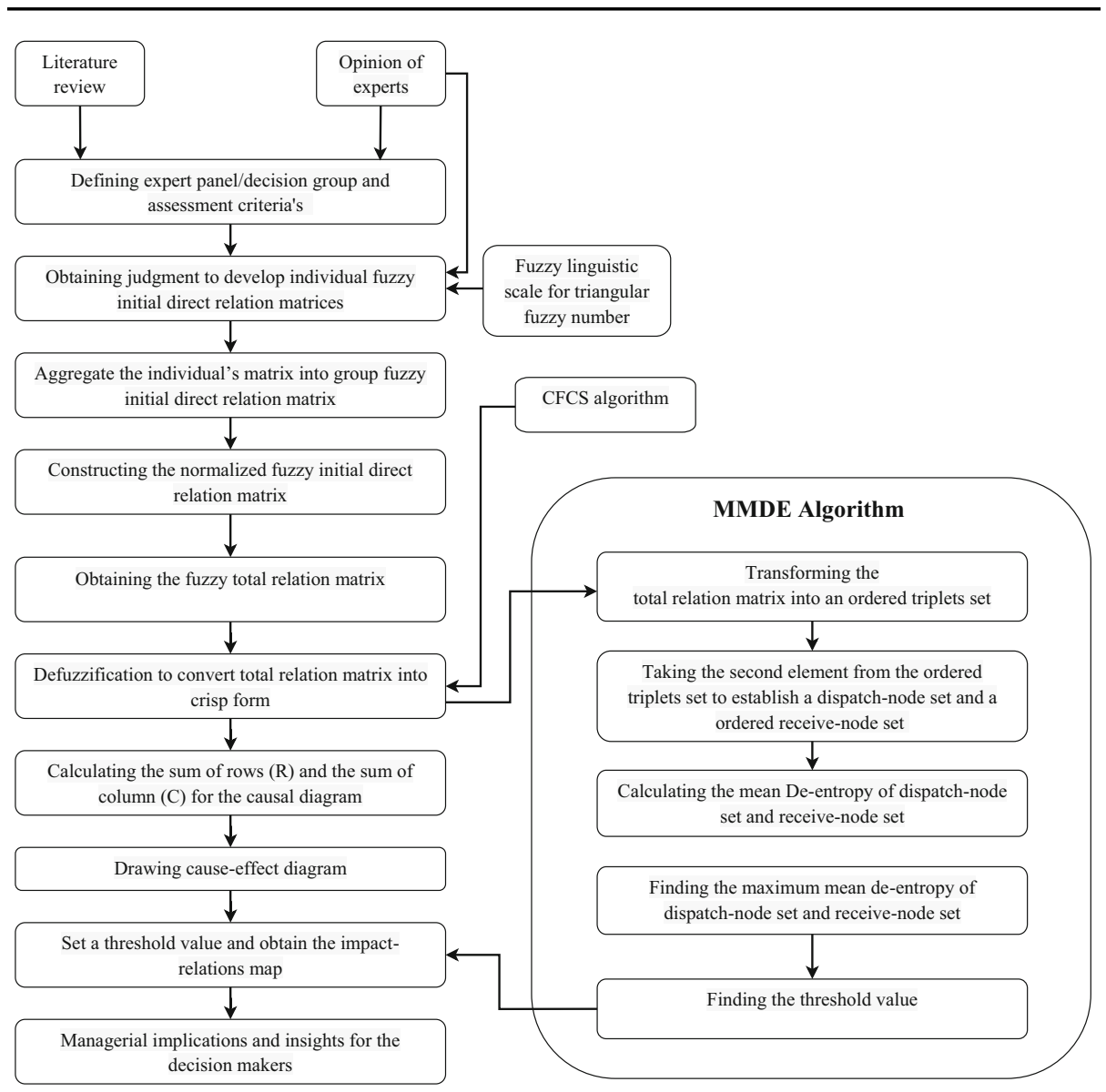

Fig. 1 Research framework for the Study

Table 3 Introduction of decision-makers (DMs) with their organization

\begin{tabular}{llll}
\hline Decision-maker & Designation & Years of experience & Organization \\
\hline DM 1 & Supply Chain Manager & 13 years & Electronics goods industry \\
DM 2 & Executive Engineer & 18 years & Electronics goods industry \\
DM 3 & Production Manager & 11 years & Automobile industry \\
DM 4 & Policy Maker & 21 years & Government \\
DM 5 & General manager & 15 years & Automobile industry \\
DM 6 & Managing Director & 17 years & Leather industry \\
DM 7 & Production Manager & 13 years & Leather industry \\
\hline
\end{tabular}


Table 4 Linguistic scale for fuzzy DEMATEL

\begin{tabular}{ll}
\hline Linguistic variable & Triangular fuzzy numbers \\
\hline No influence (No) & $(0,0,0.25)$ \\
Very low influence (VL) & $(0,0.25,0.50)$ \\
Low influence (L) & $(0.25,0.50,0.75)$ \\
High influence (H) & $(0.50,0.75,1.0)$ \\
Very high influence (VH) & $(0.75,1.0,1.0)$ \\
\hline
\end{tabular}

The electronic goods industry is selected for the survey since recycling and recovery of products adopted in the electronic goods can be employed as secondary raw material in other arrangements. BCT has the potential to track the products in a secure cloud system that makes the industry a more apparent and safer place (Lee \& Pilkington, 2017). Also, experts from leather industry are elected for the survey. The leather industry is one of the most polluted manufacturing industries. Thus, there is a requirement to assess the environmental sustainability in the leather supply chain. The application of BCT allows traceability from raw material to final manufactured product. Also, supply chain traceability refers to improved environmental sustainability (Marconi et al., 2017). Further, BCT adoption encourages enhanced coordination among the different stakeholders (Karuppiah et al., 2021). In the automobile industry, value is created through transactions and contracts in business networks that construct a flow of products and services (Kamble et al., 2021). BCT provides organizations with increased supply chain visibility and transparency in transactions (Ivanov et al., 2019). Therefore, experts from the automobile industry are included in the survey analysis. The DMs adopted a set of fuzzy numbers and fuzzy membership functions to judge the potential BRCs in Table 4. The pairwise comparison was prepared for a single decision-maker adopting the linguistic variables.

\subsection{Fuzzy DEMATEL methodology}

The DEMATEL method was advanced in 1973 by the Battelle Memorial Institute through the Geneva Research Centre. The DEMATEL methodology was employed to interpret the interactions among the complex criteria. DEMATEL is an MCDM approach that handles the decision-making problem and associates it with other methodologies to generate more acceptable results for the problem (Lee and Lin, 2013). Human decisions have ambiguity and vagueness in their criteria. The implementation of the fuzzy set theory in the DEMATEL technique prevents incomplete and inaccurate information from being featured in human decisions (Bhatia and Srivastava, 2018). Therefore, integrating the fuzzy logic during the data collection could be a solution to cater this problem. However, the DEMATEL results contain redundant information, challenging researchers to analyze their research problems (Li \& Tzeng, 2009). Therefore, the MMDE algorithm is combined with DEMATEL to determine the threshold values to identify the BRCs for PRS, which can shorten the quantity of information with the concept of entropy. In past studies, the combined fuzzy DEMATEL-MMDE methodology is employed by the researchers, such as barriers of IoT's implementation in the manufacturing industry (Singh \& Bhanot, 2020), identifying the best design criteria for an individual product (Younesi and Roghanian, 2015), ranking the financial ratios in shipping companies (Lee and Lin, 2013), and the like. 
The present study adopted the fuzzy DEMATEL method to increase the accuracy of the analysis. The recommendations of the industry professionals and academicians were obtained through a questionnaire, where the BRCs for PRS were arranged to adopt a fuzzy linguistic range in Table 4.

The steps for the fuzzy DEMATEL approach are presented as follows.

\subsubsection{Building of average direct relation matrix}

In this step, a fuzzy linguistic scale was adopted to discover the interactions among the $i-j$ th factor, as highlighted in Table 4. Further, the fuzzy triangular numbers and aggregate the fuzzy numbers were consigned. De-fuzzification was performed by transforming the fuzzy data into crisp scores (CFCS) (Opricovic \& Tzeng, 2003).

Let, $\widetilde{A_{i j}^{n}}=\left(a_{i j}^{n}, b_{i j}^{n}, c_{i j}^{n}\right)$, and influence matrix is determined as,

$$
\tilde{A}^{n}=\left[\begin{array}{c}
0 \tilde{A}_{12}^{n} \tilde{A}_{13}^{n} \ldots \tilde{A}_{1 m}^{n} \\
\tilde{A}_{21}^{n} 0 \tilde{A}_{23}^{n} \ldots . \tilde{A}_{2 m}^{n} \\
\ldots . \\
\ldots . \\
\tilde{A}_{m 1}^{n} \tilde{A}_{m 2}^{n} \tilde{A}_{m 3}^{n} \ldots 0
\end{array}\right], n=1,2,3 \ldots, h,
$$

where $m$ is the number of criteria, and $h$ is the number of experts.

The step-wise algorithm of the CFCS process is presented as:

Normalization:

$$
\begin{aligned}
& x c_{i j}^{n}=\left(c_{i j}^{n}-\min a_{i j}^{n}\right) / \Delta_{\min }^{\max } \\
& x b_{i j}^{n}=\left(b_{i j}^{n}-\min a_{i j}^{n}\right) / \Delta_{\min }^{\max } \\
& x a_{i j}^{n}=\left(a_{i j}^{n}-\min a_{i j}^{n}\right) / \Delta_{\min }^{\max }
\end{aligned}
$$

where $\Delta_{\min }^{\max }=\max c_{i j}^{n}-\min a_{i j}^{n}$.

Determine the right-side and left side normalized values:

$$
\begin{aligned}
x c s_{i j}^{n} & =\frac{x c_{i j}^{n}}{\left(1+x c_{i j}^{n}-x b_{i j}^{n}\right)} . \\
x a s_{i j}^{n} & =\frac{x b_{i j}^{n}}{\left(1+x b_{i j}^{n}-x a_{i j}^{n}\right)}
\end{aligned}
$$

Determine the total normalized crisp values:

$$
x_{i j}^{n}=\left[x a s_{i j}^{n}\left(1-x a s_{i j}^{n}\right)+x c s_{i j}^{n} \times x c s_{i j}^{n}\right] / 1-x c s_{i j}^{n} \times x c s_{i j}^{n}+x c s_{i j}^{n}
$$

Determine the crisp values:

$$
z_{i j}^{n}=\min a_{i j}^{n}+x_{i j}^{n} \times \Delta_{\min }^{\max }
$$

Relate the crisp values:

$$
z_{i j}=\frac{1}{h}\left(z_{i j}^{1}+z_{i j}^{2}----z_{i j}^{h}\right)
$$




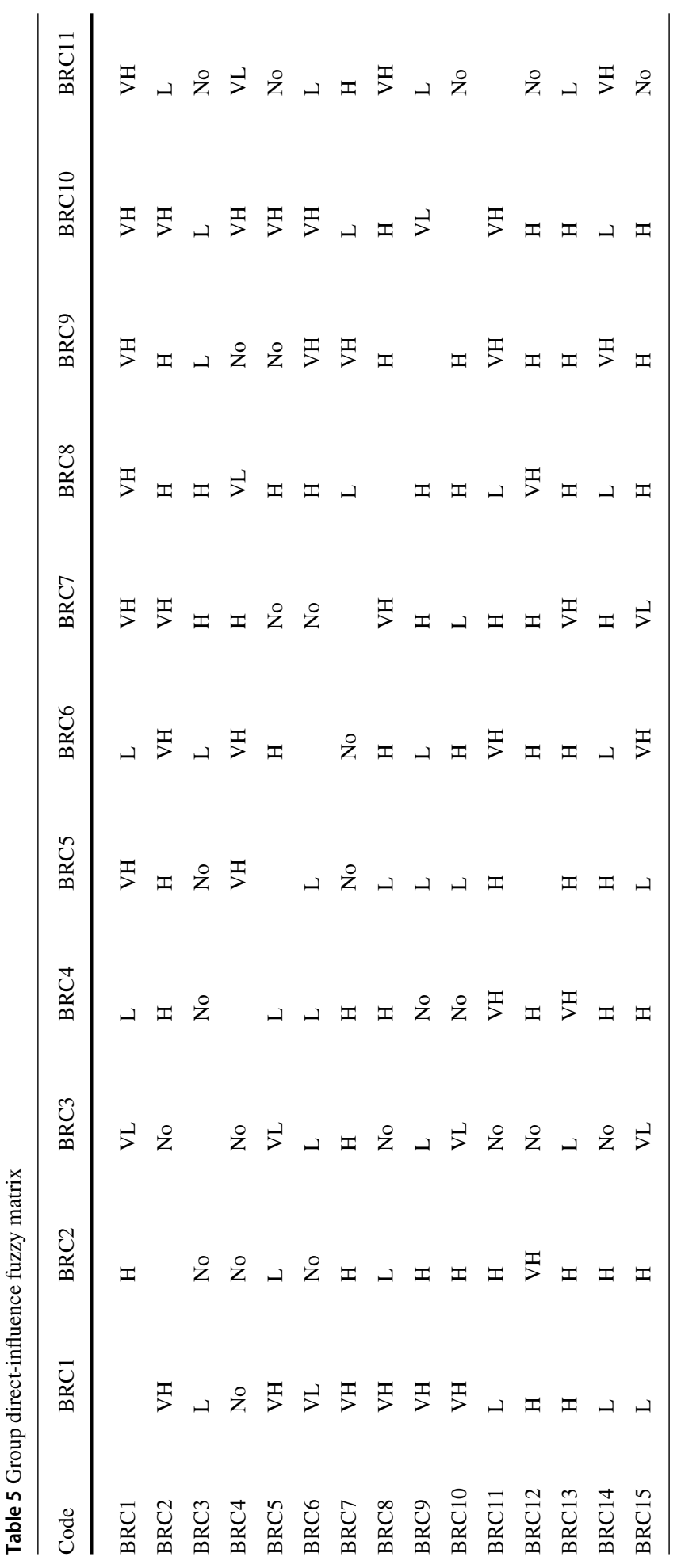




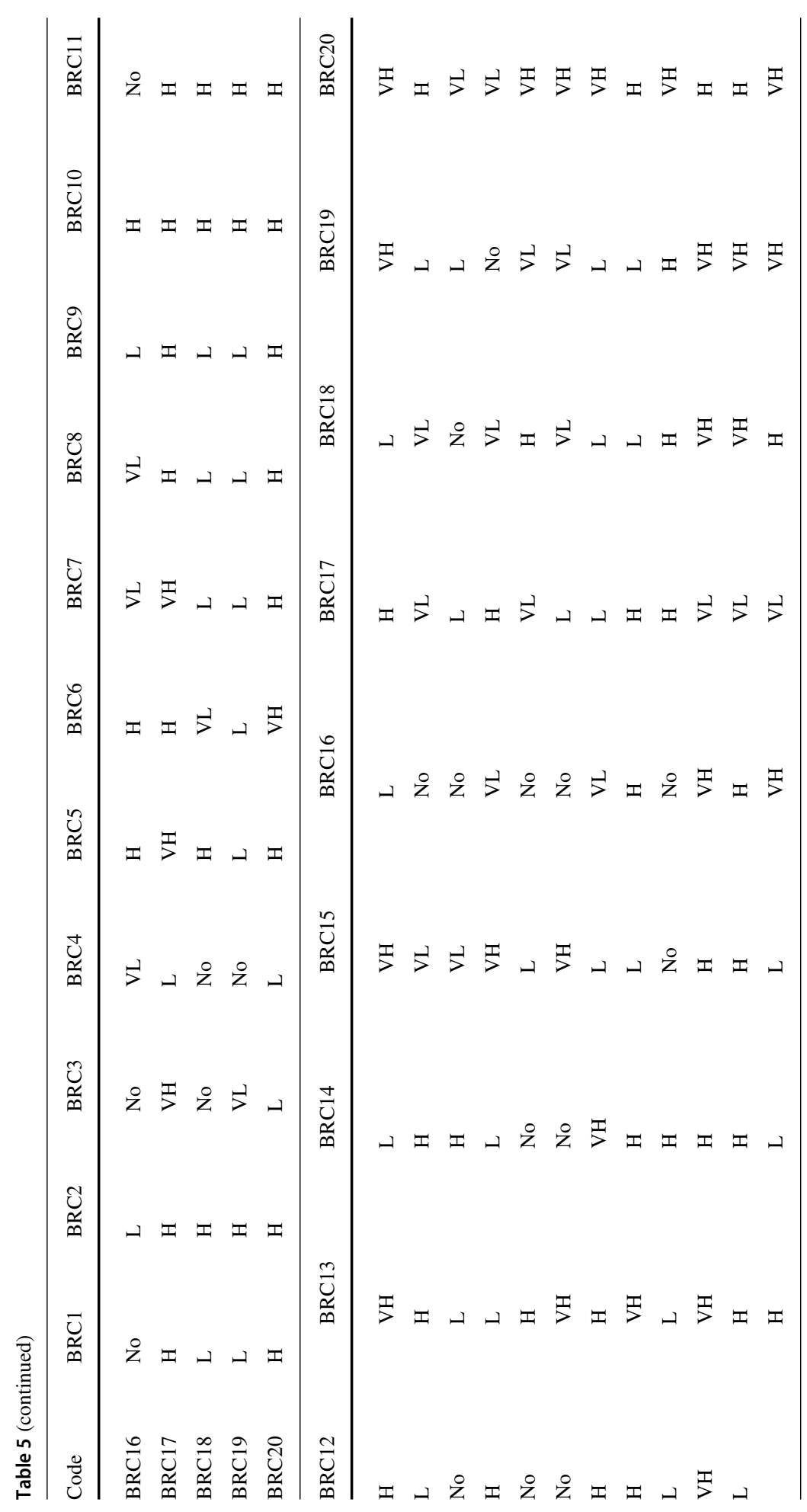




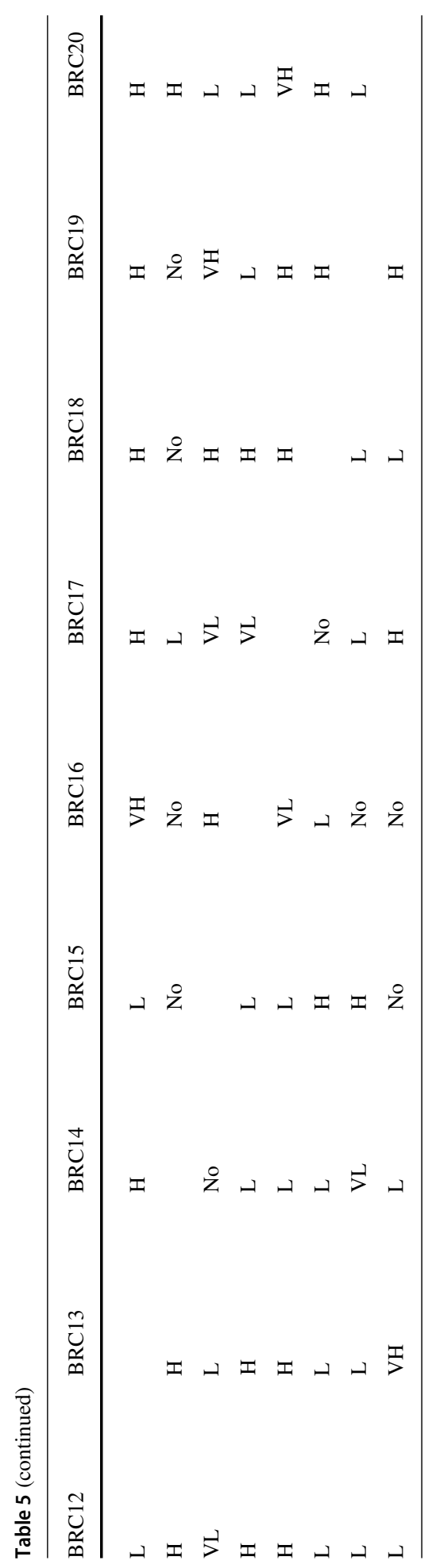


As shown in Eq. (10), the group direct-influence fuzzy matrix was obtained by assigning the linguistic variables for each identified BRC to PRS in Table 5.

$$
Z=\left[z_{i j}\right]
$$

\subsubsection{Normalization of direct relation matrix}

The normalized direct-influence fuzzy matrix $X$ was attained using Eq. (11), and data are presented in above Table 6.

$$
X=\lambda * Z,
$$

where

$$
\lambda=\min \left[\frac{1}{\max 1 \leq i \leq m \sum_{j=1}^{m}\left|z_{i j}\right|} ; \frac{1}{\max 1 \leq j \leq m \sum_{i=1}^{m}\left|z_{i j}\right|}\right]
$$

\subsubsection{Determination of total relation matrix}

$$
T=X(I-X)^{-1},
$$

where $\mathrm{I}$ is the identity matrix, and $\mathrm{X}$ is the normalized direct-influence fuzzy matrix.

The fuzzy total relation matrix and defuzzified total relation matrix are presented in Tables 7 and 8. In the defuzzified total relation matrix in Table 8, the sum of rows (D) and columns $(\mathrm{R})$ are obtained as:

$$
\begin{gathered}
T=\left[t_{i j}\right] m \times m, i, j=1,2, \ldots, m, \\
D=\left[\sum_{j=1}^{m} t_{i j}\right] m \times 1=\left[t_{i}\right] m \times 1 \\
R=\left[\sum_{i=1}^{m} t_{i j}\right] 1 \times m=\left[t_{j}\right] 1 \times m
\end{gathered}
$$

Later, $\mathrm{D}$ and $\mathrm{R}$ values were added and subtracted to attain the values of prominence (D + $\mathrm{R})$ and influence (D-R).

\subsubsection{Preparation of cause-and-effect diagram}

The cause-and-effect diagram highlighted the cause and effects for the BRCs for PRS. They were developed in this step using the $(\mathrm{D}+\mathrm{R})$ and $(\mathrm{D}-\mathrm{R})$ values.

\subsection{Maximum mean de-entropy (MMDE) algorithm}

In the DEMATEL methodology, the experts' recommendations were employed to find the threshold values. The determination of a logical threshold value was a tedious task. Therefore, the MMDE algorithm was suggested to obtain a threshold value for plotting the impactrelations map (Li \& Tzeng, 2009). The various steps used in the MMDE algorithm are highlighted as follows (Chen and Li, 2012): 


\begin{tabular}{|c|c|c|c|c|c|c|c|c|c|c|}
\hline & $\begin{array}{l}\overline{\bar{v}} \\
\frac{\pi}{m}\end{array}$ & 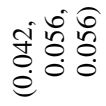 & 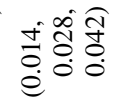 & $e^{0} \frac{\hat{\theta}}{0}$ & 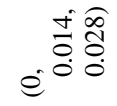 & $e^{0} \frac{\hat{\theta}}{0}$ & 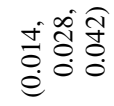 & 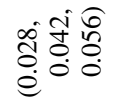 & 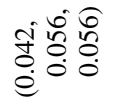 & 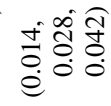 \\
\hline & $\begin{array}{l}\stackrel{0}{0} \\
\frac{\approx}{\infty}\end{array}$ & 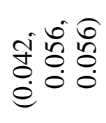 & 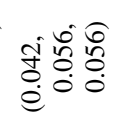 & 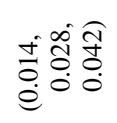 & 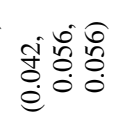 & 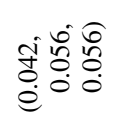 & 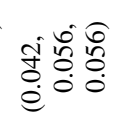 & 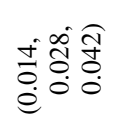 & 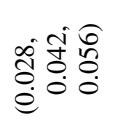 & 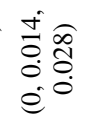 \\
\hline & $\begin{array}{l}\text { 己े } \\
\frac{0}{\infty}\end{array}$ & 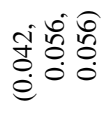 & 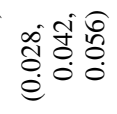 & 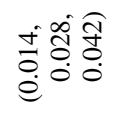 & $e^{\circ} \stackrel{\overparen{J}}{0}$ & $e^{0}$ & 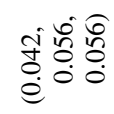 & 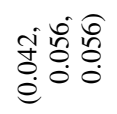 & 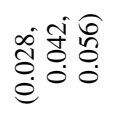 & $\begin{array}{l}\hat{0} \\
\hat{0} \\
\dot{e}\end{array}$ \\
\hline & 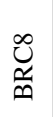 & 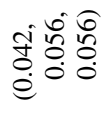 & 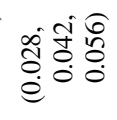 & 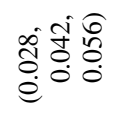 & $\begin{array}{l}\stackrel{+}{0} 0 \\
0 \\
0 \\
0 \\
0 \\
0\end{array}$ & 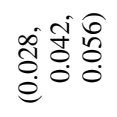 & 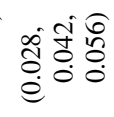 & 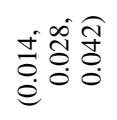 & $\begin{array}{l}0 \\
0 \\
0 \\
0\end{array}$ & 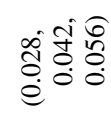 \\
\hline & $\begin{array}{l}\hat{0} \\
\stackrel{y}{m}\end{array}$ & 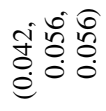 & 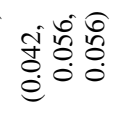 & 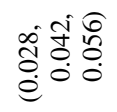 & 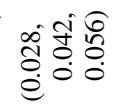 & $\begin{array}{l}e^{-\frac{\hat{\theta}}{0}} \\
0.0 \\
e^{-0}\end{array}$ & 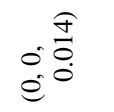 & $\begin{array}{l}\hat{0} \\
0 \\
0 \\
0\end{array}$ & 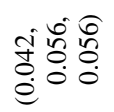 & 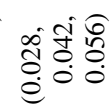 \\
\hline & 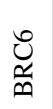 & 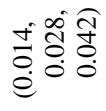 & 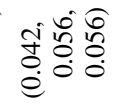 & 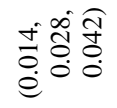 & 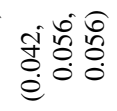 & 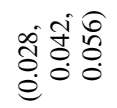 & $\begin{array}{l}\hat{0} \\
0 \\
\hat{e}\end{array}$ & $e^{i} \frac{\hat{\sigma}}{0}$ & 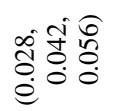 & 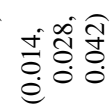 \\
\hline & 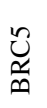 & 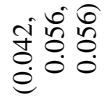 & 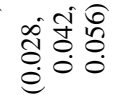 & $\begin{array}{l}\stackrel{\widehat{J}}{0} \\
0 \\
e^{\circ}\end{array}$ & 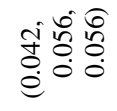 & $\begin{array}{l}\hat{0} \\
0 \\
\dot{e}\end{array}$ & 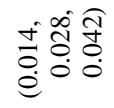 & $e^{0} \frac{\hat{f}}{0}$ & 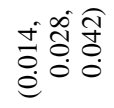 & 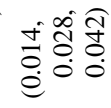 \\
\hline & $\underset{\substack{ \pm \\
\hdashline}}{J}$ & 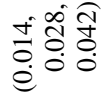 & 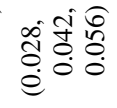 & 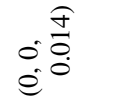 & $\begin{array}{l}\hat{0} \\
0 \\
0 \\
0\end{array}$ & 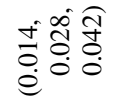 & 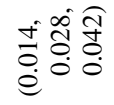 & 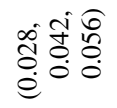 & 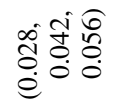 & $e^{-\frac{\hat{\theta}}{0}}$ \\
\hline & 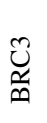 & $\begin{array}{l}\dot{+} \widehat{O} \\
\dot{0} \\
\dot{0} \\
e^{:}\end{array}$ & 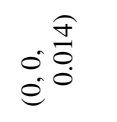 & $\begin{array}{l}\hat{0} \\
0 \\
\dot{0}\end{array}$ & 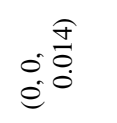 & 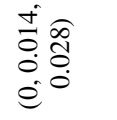 & 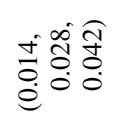 & 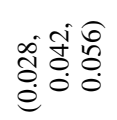 & $\begin{array}{l}e^{\circ} \frac{\hat{\theta}}{0} \\
e^{0}\end{array}$ & 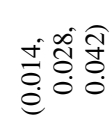 \\
\hline$\stackrel{\Xi}{0}$ & $\underset{\circlearrowright}{\tilde{N}}$ & $\begin{array}{ll} & 0 \\
0 & 0 \\
0 & 0 \\
0 & 0 \\
0 & 0 \\
0 & 0\end{array}$ & $\begin{array}{l}0 \\
0 \\
0 \\
0\end{array}$ & $e^{\stackrel{\partial}{\Xi}}$ & $e^{\stackrel{\partial}{0}}$ & 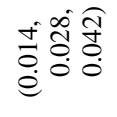 & $e^{i} e^{\stackrel{\partial}{0}}$ & 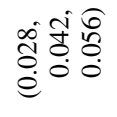 & 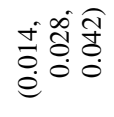 & 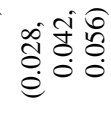 \\
\hline 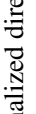 & $\begin{array}{l}\bar{v} \\
\stackrel{\sim}{\infty}\end{array}$ & $\begin{array}{l}0 \\
0 \\
0 \\
0\end{array}$ & 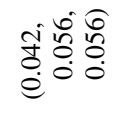 & 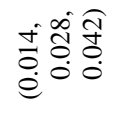 & 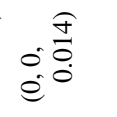 & 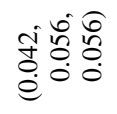 & 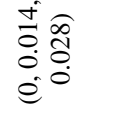 & 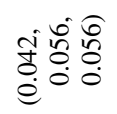 & 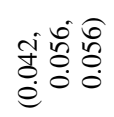 & 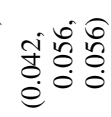 \\
\hline o & ن & $\begin{array}{l}\bar{y} \\
\vec{n}\end{array}$ & $\begin{array}{l}\tilde{N} \\
\text { 叫 }\end{array}$ & $\begin{array}{l}\tilde{y} \\
\underline{m}\end{array}$ & $\begin{array}{l}\text { U } \\
\frac{N}{n}\end{array}$ & $\begin{array}{l}0 \\
\tilde{n} \\
0\end{array}$ & 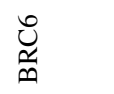 & $\begin{array}{l}\hat{y} \\
\bar{n}\end{array}$ & $\begin{array}{l}\bigcup_{0}^{\infty} \\
\frac{n}{m}\end{array}$ & yे \\
\hline
\end{tabular}




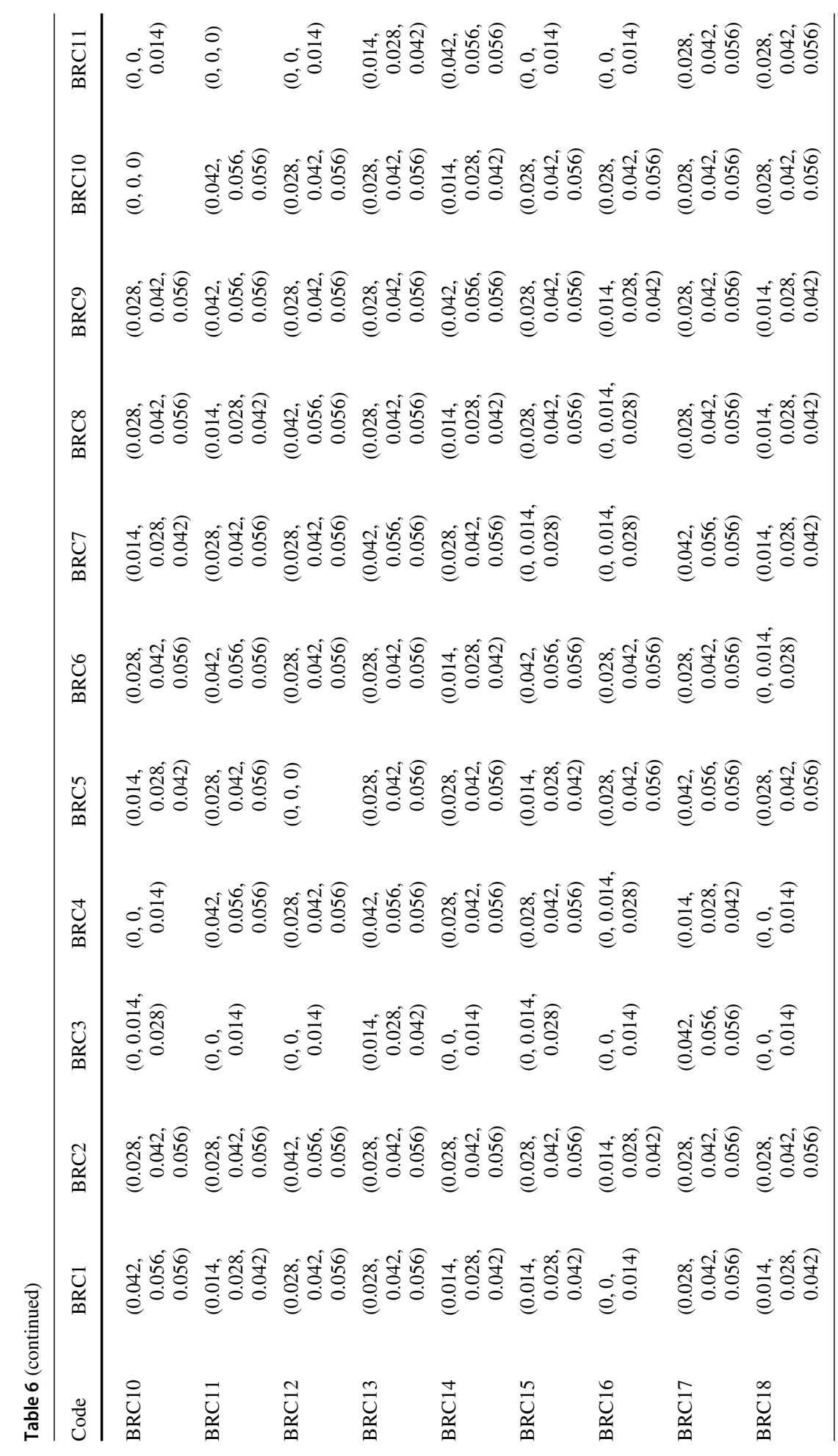




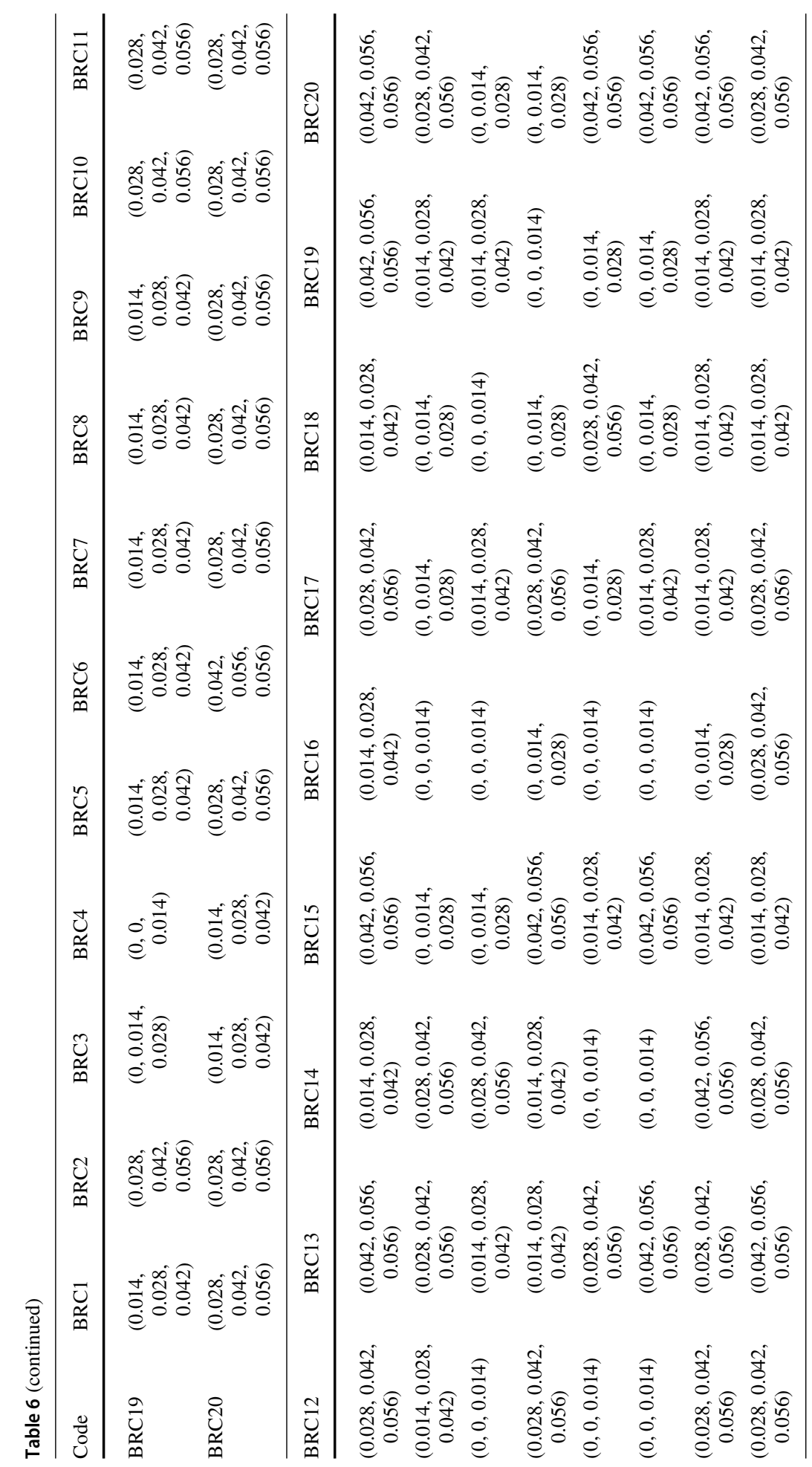




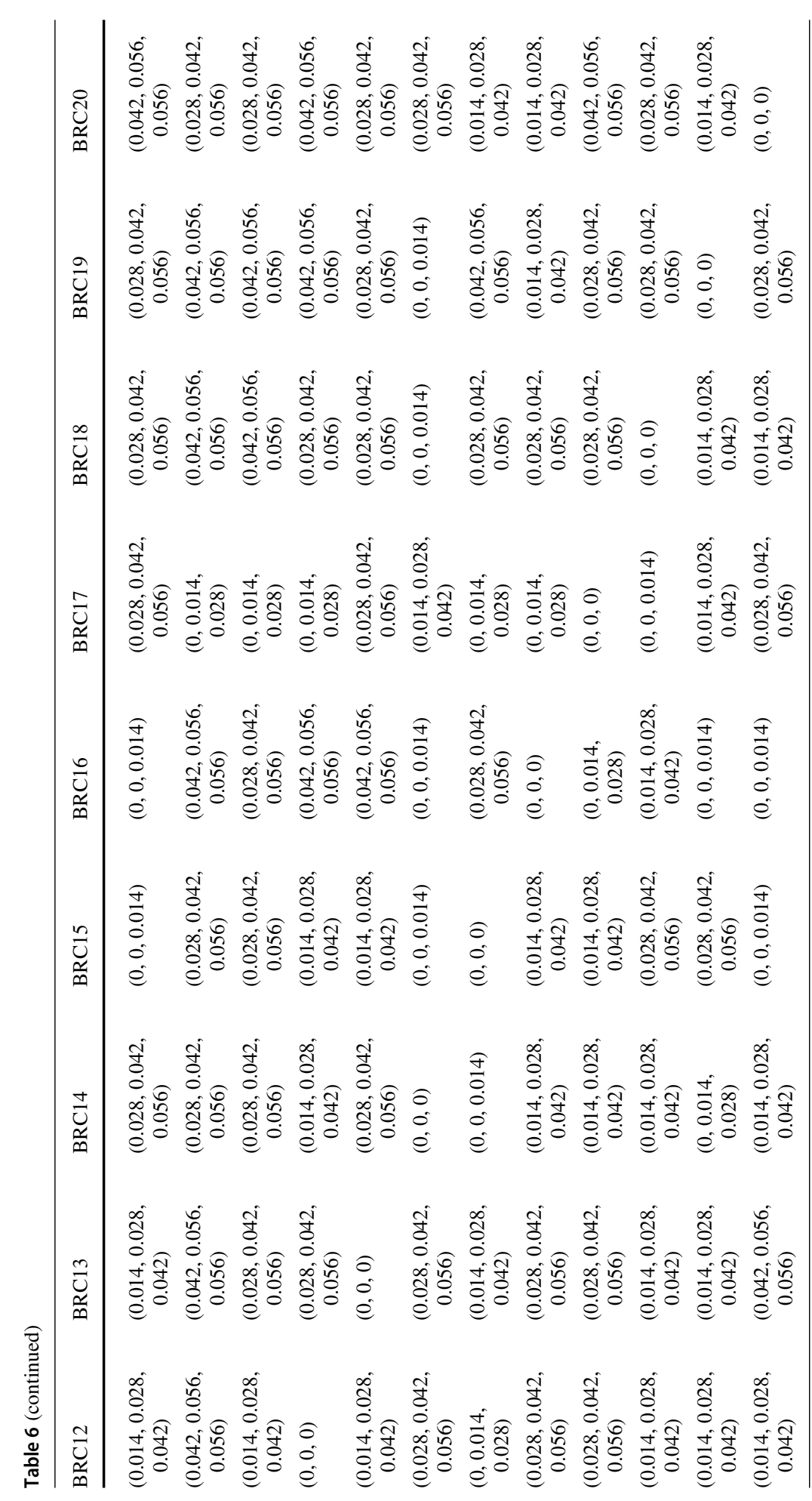




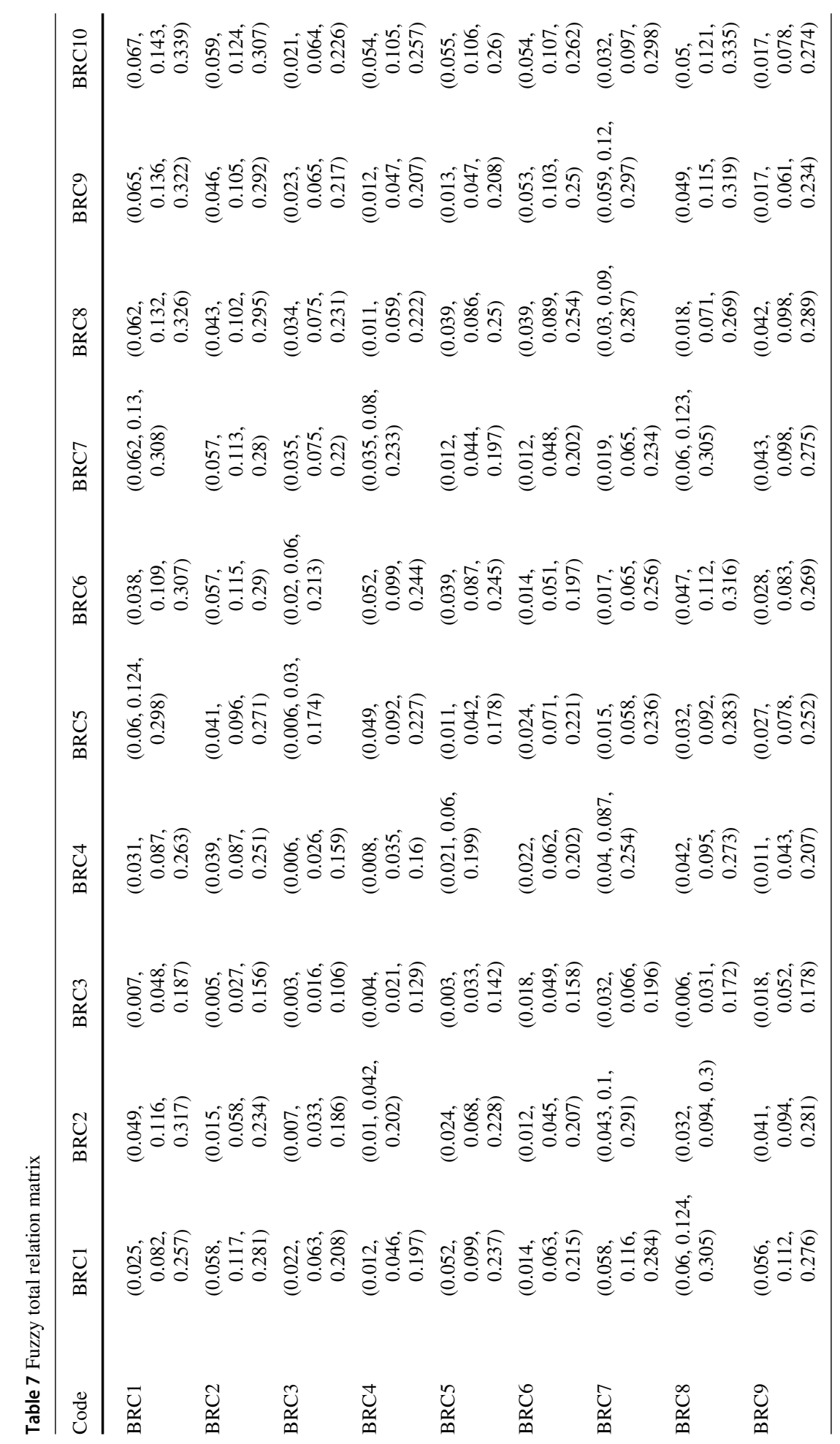




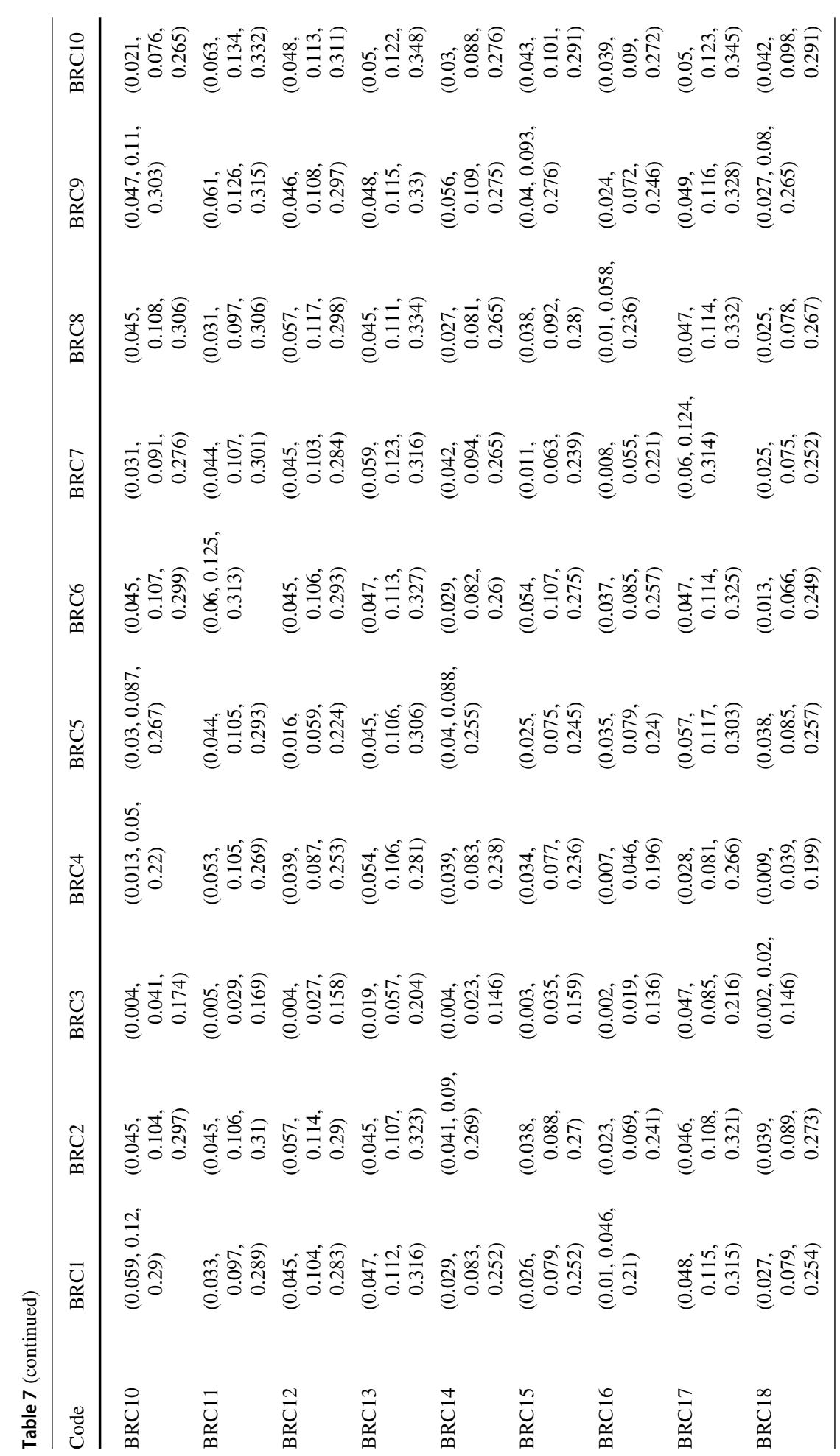




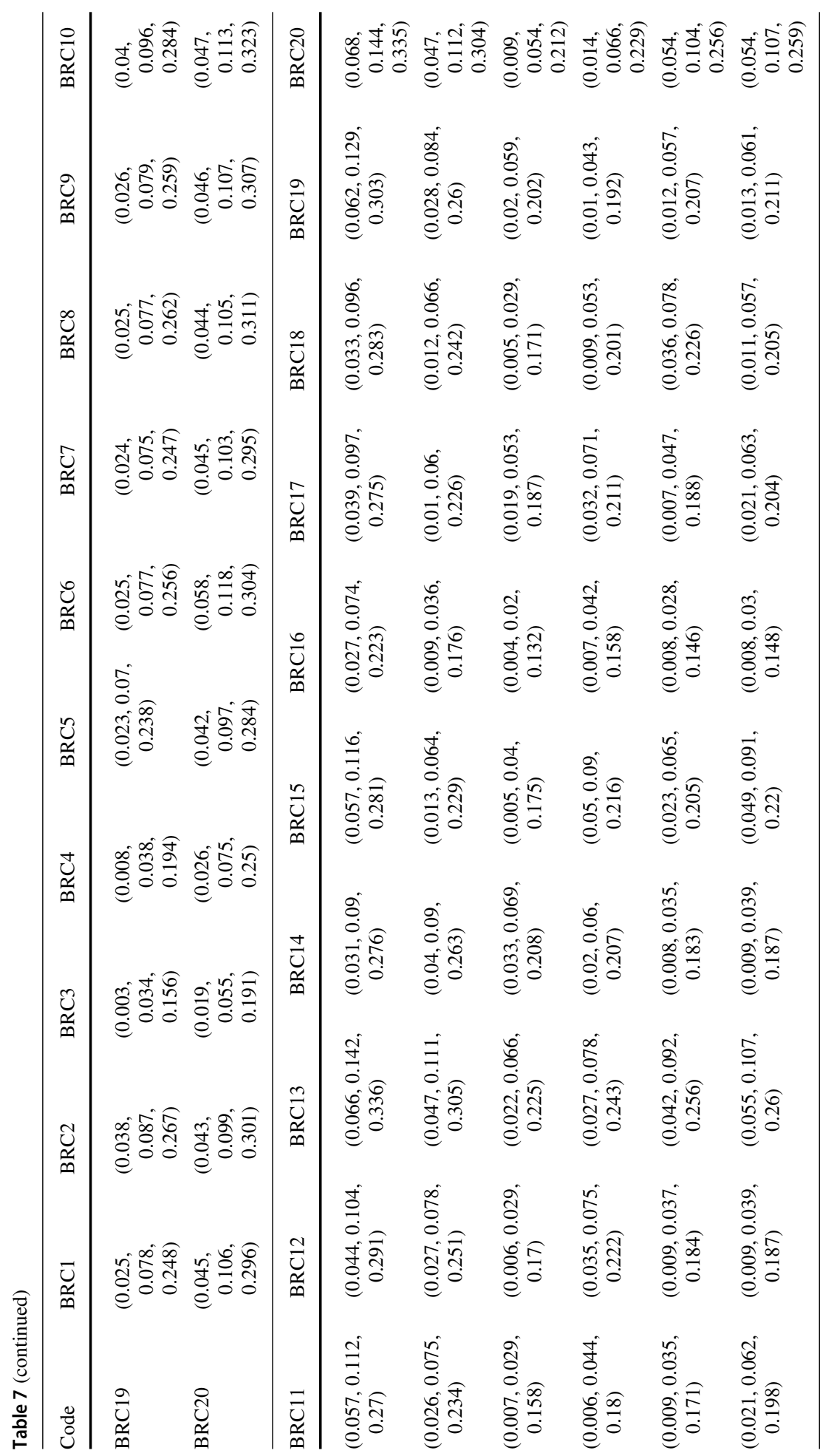




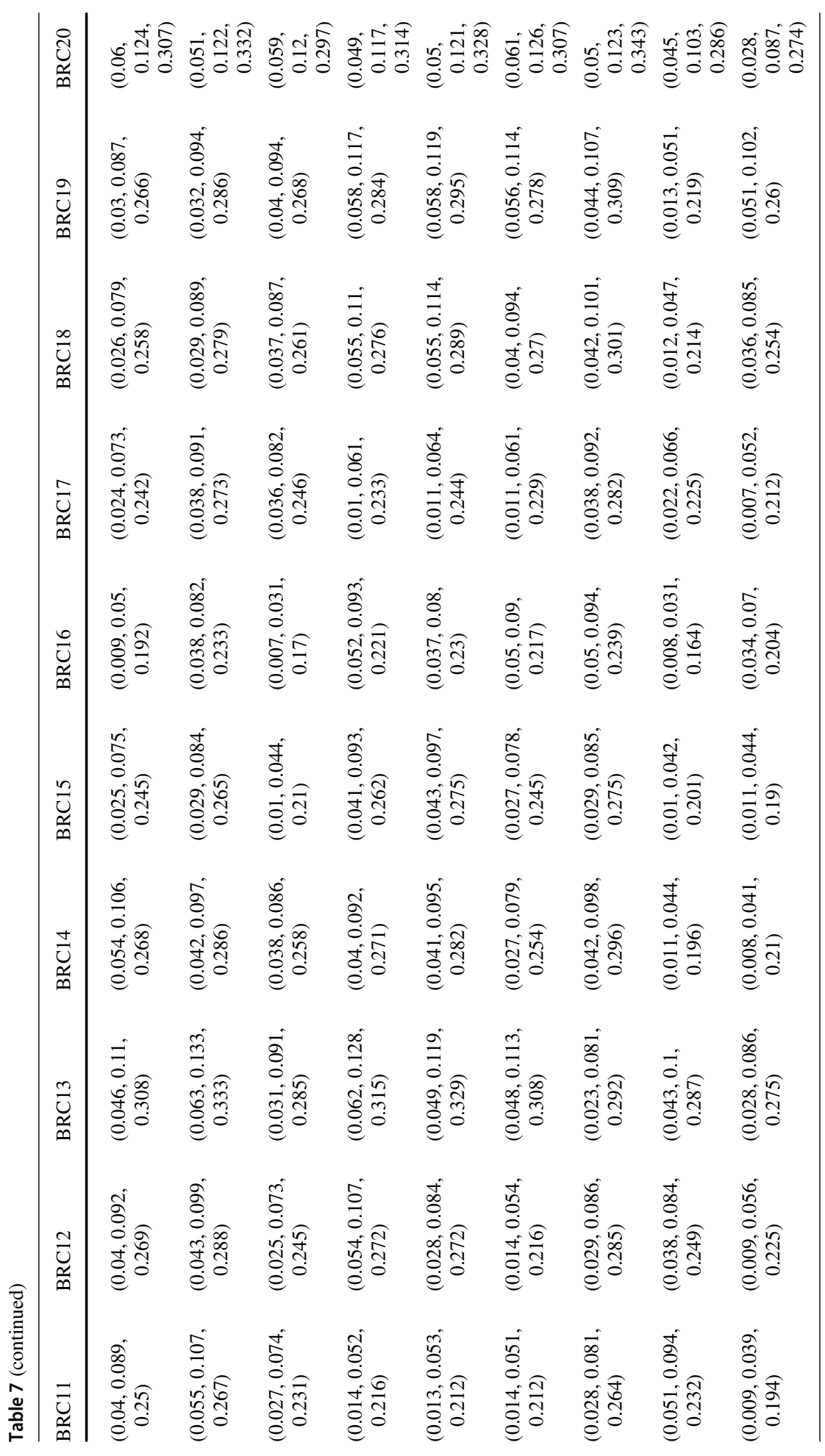




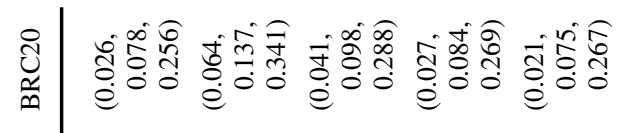

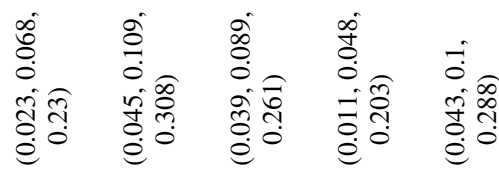

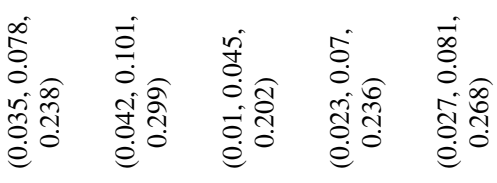

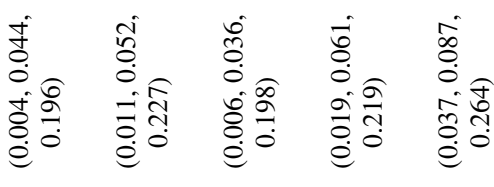

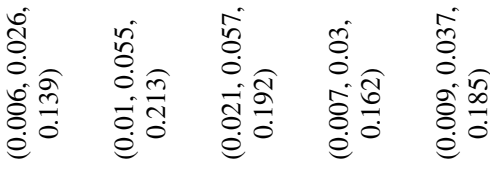

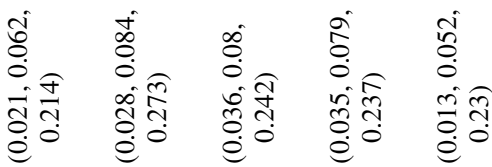

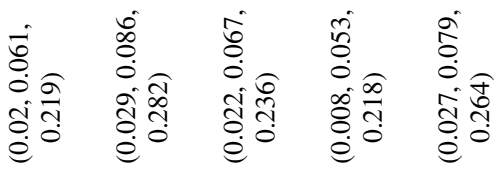

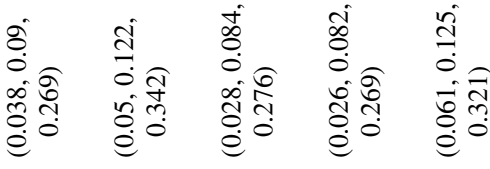

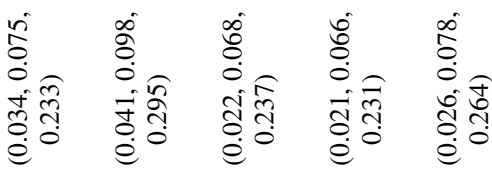

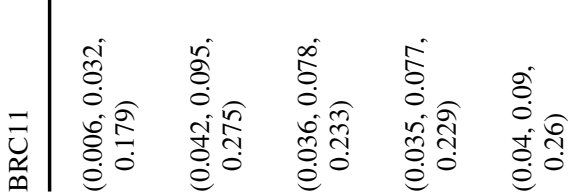




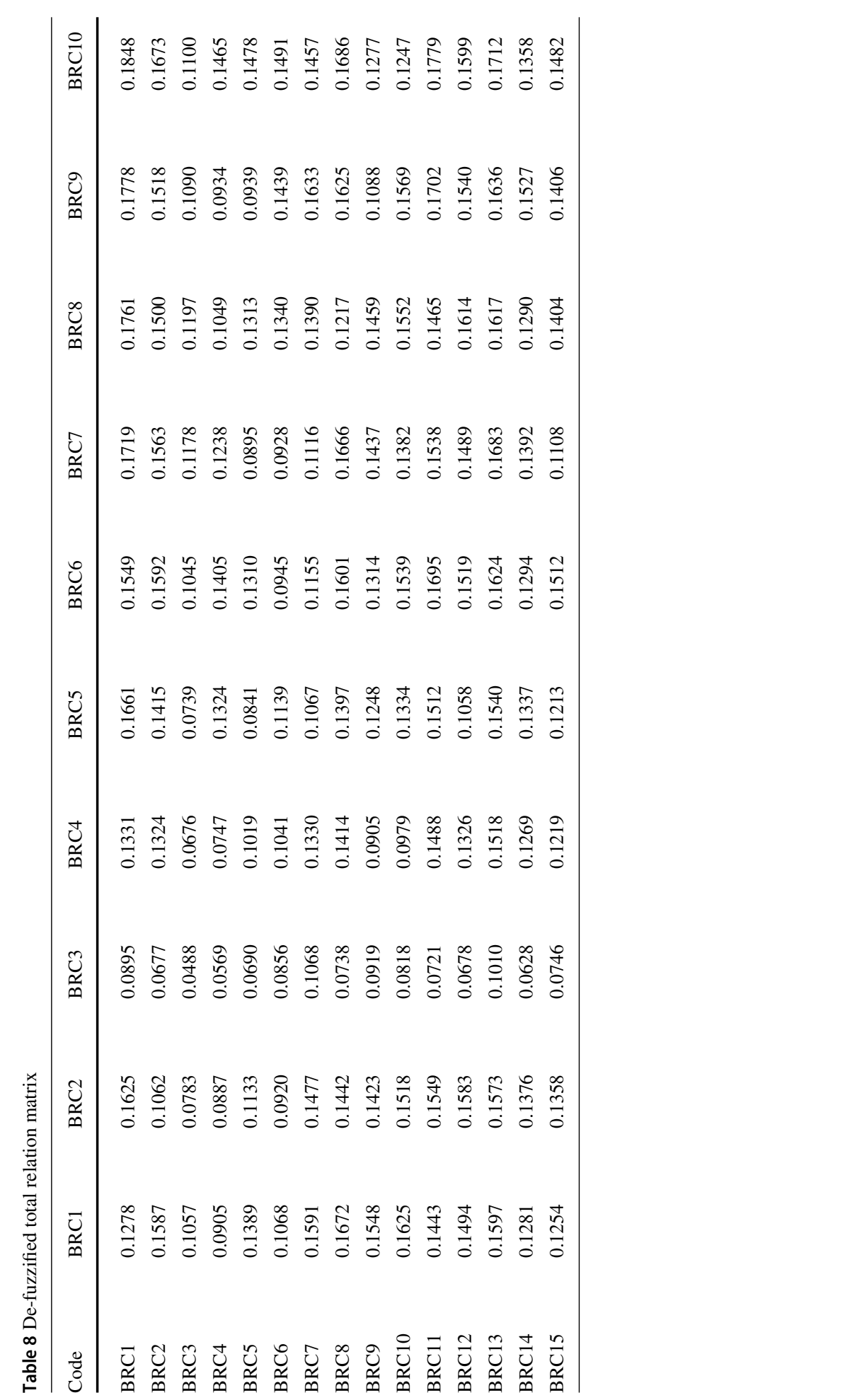




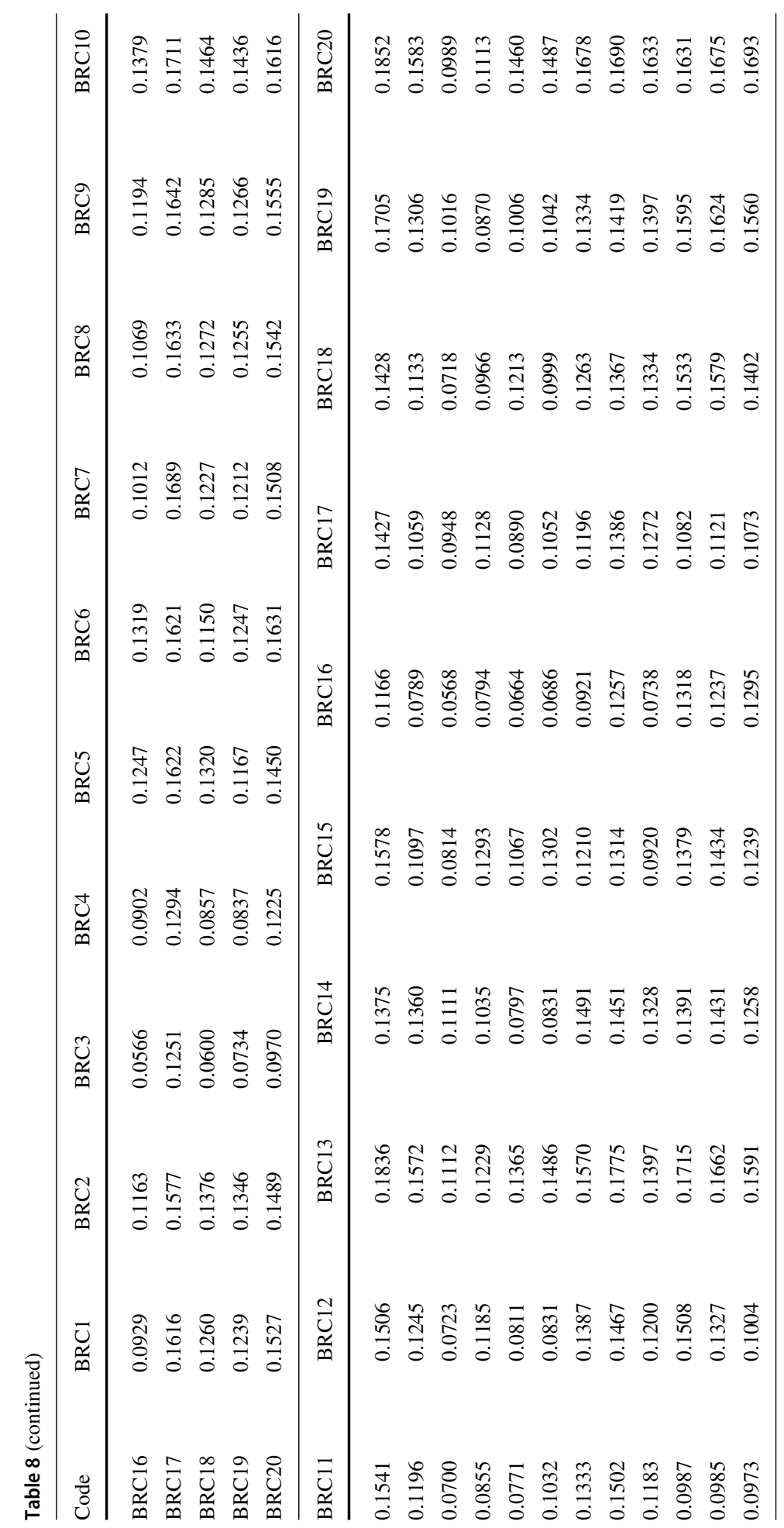




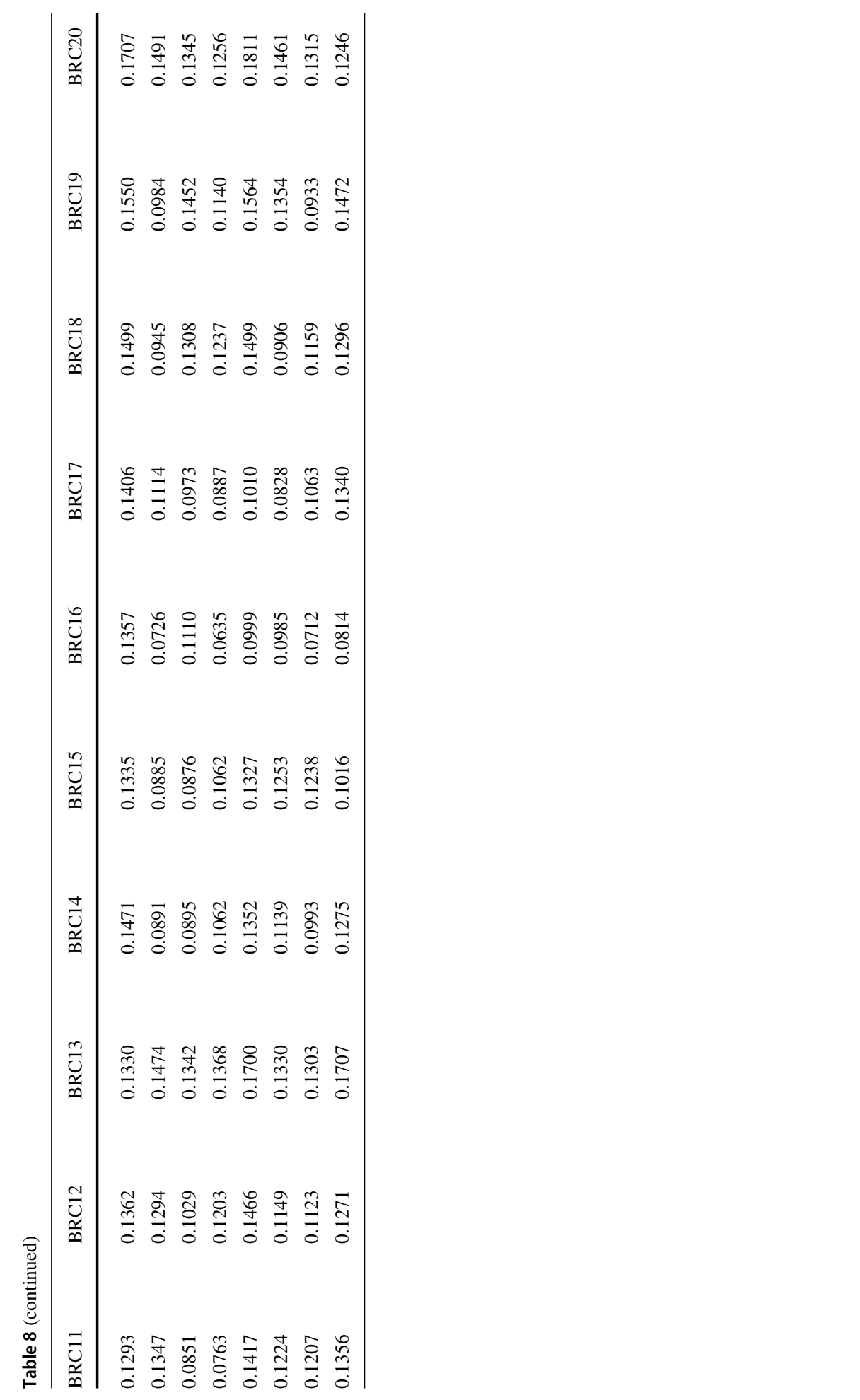


Table 9 The dispatch node set calculation

The ordered triplets set

The Dispatch Node set $T^{D i}$

$M D E_{t}^{D i}$ values

Maximum $M D E_{t}^{D i}$

Corresponding $T_{t}^{D i}$
$\{(0.1852,1,20),(0.1848,1,10),(0.1836,1,13),(0.1811,17,20),(0.1779$, $11,10),(0.1778,1,9) \ldots,(0.0664,5,16),(0.0635,16,16),(0.0628,14,3)$, $(0.06,18,3),(0.0569,4,3),(0.0568,3,16),(0.0566,16,3),(0.0488,3,3)\}$

$\{1,1,1,17,11,1,8,1,1,10,13,17,13,20,1,11,17,11,12,8,17,8,13,7$, $11,2 \ldots, 11,3,19,3,5,6,12,2,3,5,16,14,18,4,3,16,3\}$

$\{0,0,0,0.0654,0.0494,0.077,0.0581,0.0782,0.0959,0.0764,0.0619$, $0.053,0.0445, \ldots, 0.0001,0.0001,0.0001,0.0001,0.0001,0.0001,0.0001$, $0.0001,0\}$

0.095894

$\{1,1,1,17,11,1,8,1,1\}=\{1,17,11,8\}$

\subsubsection{Transforming the defuzzified total relation matrix in Table 8 into an ordered triplet set 0}

\subsubsection{Determining the second component from the set $\mathbf{O}$ generates a new set called ordered Dispatch node set D}

\subsubsection{Approximating the mean de-entropy (MDE) value for elements of the dispatch node set}

Considering the first $t$ elements of $T^{D i}$ as a new set $T_{t}^{D i}$ t, we allocated the probability of different elements and then calculated the de-entropy $H^{D}$ of the set by adopting Eqs. (16) and (17). At first, the value of $t$ was put as 1 , and the value of $t$ was increased by 1 up to the total number of elements.

$$
H^{D}=H\left(\frac{1}{n}, \frac{1}{n}, \ldots, \frac{1}{n}\right)-H\left(p_{1}, p_{2}, \ldots, p_{n}\right)
$$

Here, $n$ is the number of elements, and $p_{n}$ is the probability of $n t h$ element

$$
M D E_{t}^{D i}=\frac{H_{t}^{D i}}{N\left(T_{t}^{D i}\right)}
$$

\subsubsection{Determining the maximum value of mean de-entropy of a dispatch node set}

The selection of the highest value from the set of $M D E_{t}^{D i}$ values and the corresponding $T_{t}^{D i}$ is provided in Table 9 .

\subsubsection{Calculating the received node sets}

Steps 3.3.2 to 3.3.4 are repeated to obtain an ordered receive node-set $T^{\mathrm{Re}}$. The receiving node set calculation is provided in Table 10 . 
Table 10 Receiving node set calculation

The ordered triplets set

The Receive Node set $T^{\text {Re }}$

$M D E_{t}^{\mathrm{Re}}$ values

Maximum $M D E_{t}^{\mathrm{Re}}$

Corresponding $T_{t}^{\mathrm{Re}}$
$\{(0.1852,1,20),(0.1848,1,10),(0.1836,1,13),(0.1811,17,20),(0.1779$, $11,10),(0.1778,1,9) \ldots,(0.0664,5,16),(0.0635,16,16),(0.0628,14,3)$, $(0.06,18,3),(0.0569,4,3),(0.0568,3,16),(0.0566,16,3),(0.0488,3,3)\}$

$\{20,10,13,20,10,9,13,8,7,13,10,10,20,13,19,9,13,6, \ldots, 16,11,3$, $16,3,3,4,16,16,3,3,3,16,3,3\}$

$\{0,0,0,0.0196,0.0146,0.0142,0.0086,0.01,0.0094,0.016,0.0199$, $0.0265, \ldots, 0.0005,0.0005,0.0004,0.0004,0.0004,0.0003,0.0003$, $0.0003,0\}$

0.031118

$\{20,10,13,20,10,9,13,8,7,13,10,10,20,13,19,9,13,6,20,20,7,10$, $7,20,20,10,1,7,13\}=\{20,10,13,9,8,7,19,6,1\}$

\subsubsection{Determining the threshold value}

We determined $T_{\text {max }}^{D i}$ by selecting the first elements from $T^{D i}$. Similarly, we determined $T_{\max }^{R e}$. Then, $T^{T h}$ was calculated as the intersection set of $T_{\max }^{D i}$ and $T_{\max }^{R e}$. The value from the last element of $T^{T h}$ was the final threshold value.

\subsubsection{Obtain the impact-relations map}

In this step, the threshold value links in the total relation matrix were included in the impact relation map.

\section{Results and discussion}

In the present study, a fuzzy DEMATEL approach was employed to examine the most substantial BRCs for the implementation of PRS. Further, the identified BRCs were ranked concerning their prominence based on the $(\mathrm{D}+\mathrm{R})$ values as follows: $\mathrm{BRC} 13>\mathrm{BRC} 1>$ $\mathrm{BRC} 10>\mathrm{BRC} 20>\mathrm{BRC} 8>\mathrm{BRC} 7>\mathrm{BRC} 9>\mathrm{BRC} 2>\mathrm{BRC} 17>\mathrm{BRC} 11>\mathrm{BRC} 12>\mathrm{BRC} 6$ $>$ BRC19 > BRC18 > BRC14 > BRC15 > BRC5 > BRC4 > BRC16 > BRC3 (Table 11).

This study presents the cause-and-effect diagram between the identified potential BRCs for PRS in Fig. 2.

\subsection{Cause-and-effect group BRCs}

The BRCs for PRS comprising of positive values were mentioned as the cause group BRCs. These were the most influencing BRCs that obstruct the implementation of PRS. Based on the (D-R) value, the cause group BRCs were organized as highlighted in Table 11. The cause BRCs were ranked as $\mathrm{BRC} 17>\mathrm{BRC} 11>\mathrm{BRC} 1>\mathrm{BRC} 12>\mathrm{BRC} 16>\mathrm{BRC} 3>\mathrm{BRC} 8>$ BRC15. Further, the BRCs with negative values were mentioned as effect group BRCs. The effect group BRCs were organized based on the (D-R) value, as highlighted in Table 11. The effect $\mathrm{BRCs}$ were ranked as BRC14 $>\mathrm{BRC} 13>\mathrm{BRC} 7>\mathrm{BRC} 2>\mathrm{BRC} 18>\mathrm{BRC} 4>\mathrm{BRC} 10$ $>$ BRC20 > BRC9 > BRC19 > BRC5 > BRC6. 
Table 11 The score for each BRC for PRS

\begin{tabular}{|c|c|c|c|c|c|c|c|}
\hline Code & $\begin{array}{l}\text { Blockchain } \\
\text { readiness } \\
\text { challenges } \\
(\mathrm{BRCs})\end{array}$ & $\mathrm{D}$ & $\mathrm{R}$ & $\mathrm{D}+\mathrm{R}$ & D-R & Rank & Cause/Effect \\
\hline $\mathrm{BRC} 1$ & $\begin{array}{l}\text { Inadequate } \\
\text { mechanism } \\
\text { for BCT } \\
\text { pursuit in } \\
\text { PRS }\end{array}$ & 3.086075 & 2.73583 & 5.821905 & 0.350245 & 2 & Cause \\
\hline BRC2 & $\begin{array}{l}\text { Challenges in } \\
\text { assimilating } \\
\text { PRS and BCT }\end{array}$ & 2.625129 & 2.665802 & 5.290931 & -0.04067 & 8 & Effect \\
\hline BRC3 & $\begin{array}{l}\text { Lack of } \\
\text { customer } \\
\text { cognizance } \\
\text { towards PRS } \\
\text { and BCT }\end{array}$ & 1.805217 & 1.56209 & 3.367306 & 0.243127 & 20 & Cause \\
\hline BRC4 & $\begin{array}{l}\text { Infantile } \\
\text { challenge of } \\
\text { BCT }\end{array}$ & 2.099013 & 2.270101 & 4.369114 & -0.17109 & 18 & Effect \\
\hline BRC5 & $\begin{array}{l}\text { High cost } \\
\text { linked with } \\
\text { BCT imple- } \\
\text { mentation }\end{array}$ & 2.105082 & 2.563251 & 4.668333 & -0.45817 & 17 & Effect \\
\hline BRC6 & $\begin{array}{l}\text { Reluctant to } \\
\text { convert to a } \\
\text { new } \\
\text { arrangement }\end{array}$ & 2.191419 & 2.806634 & 4.998053 & -0.61521 & 12 & Effect \\
\hline BRC7 & $\begin{array}{l}\text { Lack of organi- } \\
\text { zational } \\
\text { policies and } \\
\text { frameworks } \\
\text { for BCT } \\
\text { adoption }\end{array}$ & 2.666926 & 2.698196 & 5.365121 & -0.03127 & 6 & Effect \\
\hline BRC8 & $\begin{array}{l}\text { Inadequate } \\
\text { financing for } \\
\text { PRS } \\
\text { exercises }\end{array}$ & 2.908635 & 2.794014 & 5.702649 & 0.114621 & 5 & Cause \\
\hline BRC9 & $\begin{array}{l}\text { Inadequate } \\
\text { organiza- } \\
\text { tional } \\
\text { structures to } \\
\text { support PRS }\end{array}$ & 2.501923 & 2.836575 & 5.338497 & -0.33465 & 7 & Effect \\
\hline BRC10 & $\begin{array}{l}\text { Lack of IT } \\
\text { arrangements } \\
\text { to assist PRS }\end{array}$ & 2.770232 & 3.02582 & 5.796051 & -0.25559 & 3 & Effect \\
\hline
\end{tabular}


Table 11 (continued)

\begin{tabular}{|c|c|c|c|c|c|c|c|}
\hline Code & $\begin{array}{l}\text { Blockchain } \\
\text { readiness } \\
\text { challenges } \\
(\mathrm{BRCs})\end{array}$ & $\mathrm{D}$ & $\mathrm{R}$ & $\mathrm{D}+\mathrm{R}$ & D-R & Rank & Cause/Effect \\
\hline BRC11 & $\begin{array}{l}\text { Security } \\
\text { challenges to } \\
\text { BCT imple- } \\
\text { mentation }\end{array}$ & 2.896464 & 2.251629 & 5.148092 & 0.644835 & 10 & Cause \\
\hline BRC12 & $\begin{array}{l}\text { Lack of } \\
\text { technological } \\
\text { maturity } \\
\text { towards PRS }\end{array}$ & 2.699062 & 2.408936 & 5.107998 & 0.290127 & 11 & Cause \\
\hline BRC13 & $\begin{array}{l}\text { Inadequate } \\
\text { standards for } \\
\text { PRS } \\
\text { operations }\end{array}$ & 2.981986 & 2.986471 & 5.968457 & -0.00449 & 1 & Effect \\
\hline BRC14 & $\begin{array}{l}\text { Market } \\
\text { impediments } \\
\text { and } \\
\text { uncertainty }\end{array}$ & 2.390389 & 2.393708 & 4.784097 & -0.00332 & 15 & Effect \\
\hline BRC15 & $\begin{array}{l}\text { Traceability } \\
\text { and visibility } \\
\text { concern with } \\
\text { BCT } \\
\text { adoption }\end{array}$ & 2.388329 & 2.363956 & 4.752285 & 0.024373 & 16 & Cause \\
\hline BRC16 & $\begin{array}{l}\text { Limited } \\
\text { scalability } \\
\text { with BCT } \\
\text { implementa- } \\
\text { tion in } \\
\text { PRS }\end{array}$ & 2.139273 & 1.876996 & 4.016268 & 0.262277 & 19 & Cause \\
\hline BRC17 & $\begin{array}{l}\text { Lack of } \\
\text { awareness } \\
\text { and expertise } \\
\text { towards BCT } \\
\text { adoption }\end{array}$ & 2.98002 & 2.225281 & 5.205301 & 0.75474 & 9 & Cause \\
\hline BRC18 & $\begin{array}{l}\text { Data processing } \\
\text { and storage } \\
\text { challenges } \\
\text { with BCT in } \\
\text { PRS }\end{array}$ & 2.343949 & 2.478475 & 4.822424 & -0.13453 & 14 & Effect \\
\hline BRC19 & $\begin{array}{l}\text { Privacy } \\
\text { challenges } \\
\text { with BCT }\end{array}$ & 2.27854 & 2.632442 & 4.910982 & -0.3539 & 13 & Effect \\
\hline BRC20 & $\begin{array}{l}\text { Lack of } \\
\text { governance } \\
\text { and standards }\end{array}$ & 2.730457 & 3.011916 & 5.742373 & -0.28146 & 4 & Effect \\
\hline
\end{tabular}




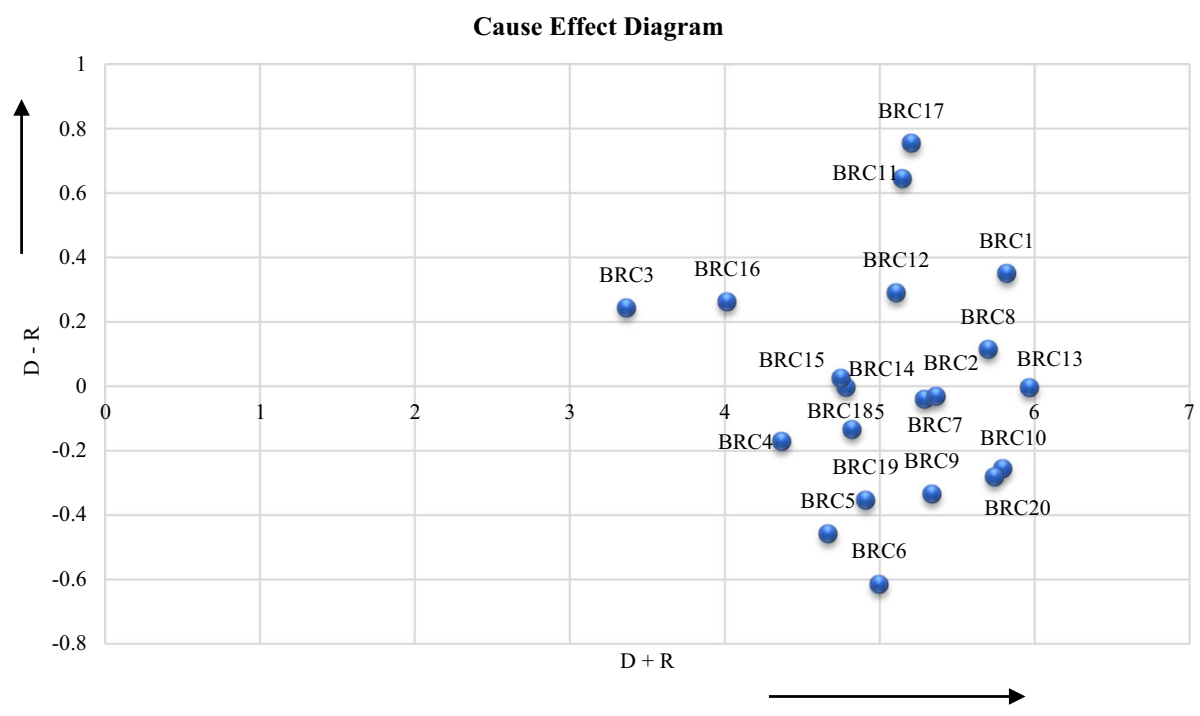

Fig. 2 Causal diagram for the BRCs for PRS

In the cause group, there were eight BRCs. Lack of awareness and expertise towards BCT adoption (BRC17) and Security challenges to BCT implementation (BRC11) were identified as the most critical BRCs that obstruct the PRS implementation. These BRCs can generate an effect on the other BRCs. The potential barrier for organizations connected with blockchain practices is a lack of awareness and understanding concerning the working of BCT (Kouhizadeh et al., 2021). Still, organizations are unaware of the potential benefits of BCT adoption in their organizations. There is a requirement for professionals to spread the knowledge among the employees regarding BCT implementation in organizations (Lopes et al., 2021). Security challenges to BCT implementation (BRC11) was among the major causal BRCs for PRS implementation. In BCT, transaction recordings are accumulated and spread in a digital ledger form comprising linked blocks of the transaction (Ye et al., 2020). There is no central management control mechanism in BCT. Several security challenges occur with BCT adoption due to the transactional setting in BCT and increased popularity.

Inadequate mechanism for BCT pursuit in PRS (BRC1) was the third-ranked causal BRC. The lack of expertise towards BCT among the organizations is a significant barrier to its implementation. The organizations successfully practicing BCT can provide precious perspectives and recommendations that can be implemented for BCT adoption in PRS. Further, synchronization and understanding among the organizations would result in enhanced BCT pursuit in PRS. This brings in the requirement for an adequate mechanism for BCT pursuit in PRS.

Lack of technological maturity towards PRS (BRC12) is another potential BRC under the cause group. BCT is accepted mainly in industries for its distinctive management of transaction settings. A lack of technological maturity for BCT is seen as one of the reasons for its unacceptance by organizations in PRS implementation (Richter et al., 2018). There is a requirement to commence several workshops and programs by the organizations to discover the BCT widely.

Limited scalability with BCT implementation in PRS (BRC16) is ranked fifth in the cause group. Scalability is necessary for organizations due to the large spread environment of 
their establishments. Organizations perform millions of transaction settings crosswise their businesses (Mazlan et al., 2020). In some cases, the limitations of scalability and a limited transaction setting in BCT contribute to substantial delays for the organizations and consumers (Biswas et al., 2018). Therefore, the scalability concern is a vital barrier to cater for efficient PRS implementation.

Lack of customer cognizance towards PRS and BCT (BRC3) is ranked sixth BRC in the cause group. The studies specific to PRS and BCT are still in a nascent stage. BCT's implementation contributes to the coordination of sustainable practices with environmental regulations (Saberi et al., 2019). Most customers relate BCT and cryptocurrency as similar. Therefore, negative thoughts against cryptocurrency occasionally transfer towards BCT (Jain et al., 2020). Lack of customer cognizance towards BCT is a barrier to its implementation in organizations.

Inadequate financing for PRS exercises (BRC8) is the seventh-ranked BRC in the causal group. Organizations are eager to invest in technologies where they expect a high return on investments. An underestimation between traditional methods and the recent era of digitalization might cause difficulty in sharing resources and decision-making regarding investments (Koc \& Bozdag, 2017). Therefore, the organizations are reluctant to invest in BCT exercises for PRS.

Traceability and visibility concern with BCT adoption (BRC15) is ranked eighth in the cause group. BCT can facilitate increased visibility and traceability through extended correlations with DSCs (Kharlamov \& Parry, 2018). The supply chain experts consider visibility and traceability essential drivers of cross-organization collaboration (Rogerson \& Parry, 2020). With technological advancements, BCT is perceived to permit ample visibility of movements along the recovery chain (Majeed \& Rupasinghe, 2017). Therefore, it becomes essential for the organizations to focus on the traceability and visibility concern with BCT adoption in PRS.

There are 12 BRCs in the effect group - the eight causal BRCs influence these 12 BRCs to implement PRS in the manufacturing industry. Market impediments and uncertainty (BRC14) was near the causal BRC group and less influenced by causal BRCs. Further, Inadequate standards for PRS operations (BRC13), Lack of organizational policies and frameworks for BCT adoption (BRC7), Challenges in assimilating PRS and BCT (BRC2), Data processing and storage challenges with BCT in PRS (BRC18), Infantile challenge of BCT (BRC4), A lack of IT arrangements to assist PRS (BRC10), Lack of Governance and standards (BRC20), Inadequate organizational structures to support PRS (BRC9), Privacy challenges with BCT (BRC19), High costs linked with BCT implementation (BRC5) and Reluctant to convert to a new arrangement (BRC6) are the BRCs in effect BRC group. These BRCs are easily influenced by the causal BRCs. To effectively implement PRS in the manufacturing industry, it is beneficial to identify the cause-and-effect BRCs. This study can assist managers in identifying these cause-and-effect relations and advance practical understandings to implement PRS in the manufacturing industry.

Further, the MMDE algorithm was applied after the DEMATEL approach to generate the threshold value. Based on MMDE analysis, the generated threshold value of 0.167248 was used to obtain the interactions among the BRCs for PRS with the most potential in Table 12.

From the MMDE analysis, an inadequate mechanism for BCT pursuit in PRS (BRC1), challenges in assimilating PRS and BCT (BRC2), reluctance to convert to a new arrangement (BRC6), a lack of organizational policies and frameworks for BCT adoption (BRC7), inadequate financing for PRS exercises (BRC8), inefficient organizational structures to support PRS (BRC9), a lack of IT arrangements to assist PRS (BRC10), security challenges for BCT implementation (BRC11), lack of technological maturity towards PRS (BRC12), inadequate 
Table 12 Threshold value

\begin{tabular}{ll}
\hline$T_{\max }^{D i}$ & $(0.185249160623833,1,20),(0.18481379363312,1,10),(0.183627937916748,1$, \\
& $13),(0.181106269457534,17,20),(0.17792210813375,11,10)$, \\
& $(0.177828008519286,1,9),(0.177471993130536,8,13)\}$ \\
$T_{\max }^{\operatorname{Re}}$ & $(0.185249160623833,1,20),(0.18481379363312,1,10),(0.183627937916748,1$, \\
& $13),(0.181106269457534,17,20),(0.17792210813375,11,10)$, \\
& $(0.177828008519286,1,9),(0.177471993130536,8,13),(0.176056355034923,1$, \\
& $8),(0.171945719696714,1,7),(0.171549518138438,10,13),(0.17122506239988$, \\
& $13,10),(0.171050417302425,17,10),(0.170746536190432,13,20)$, \\
& $(0.170667101090551,20,13),(0.170535722700878,1,19),(0.170177808166487$, \\
& $11,9),(0.169982506525479,17,13),(0.169469421016332,11,6)$, \\
& $(0.169315344097307,12,20),(0.169019917119026,8,20),(0.168934270330163$, \\
& $17,7),(0.168592226113708,8,10),(0.168319549252442,13,7),(0.167826280904$, \\
& $7,20),(0.167504953109114,11,20),(0.167322600861131,2,10)$, \\
& $(0.167247572766832,8,1)\}$ \\
\{ & $(0.185249160623833,1,20),(0.18481379363312,1,10),(0.183627937916748,1$, \\
& $13),(0.181106269457534,17,20),(0.17792210813375,11,10)$, \\
& $(0.177828008519286,1,9),(0.177471993130536,8,13),(0.176056355034923,1$, \\
& $8),(0.171945719696714,1,7),(0.171549518138438,10,13),(0.17122506239988$, \\
& $13,10),(0.171050417302425,17,10),(0.170746536190432,13,20)$, \\
& $(0.170667101090551,20,13),(0.170535722700878,1,19),(0.170177808166487$, \\
& $11,9),(0.169982506525479,17,13),(0.169469421016332,11,6)$, \\
& $(0.169315344097307,12,20),(0.169019917119026,8,20),(0.168934270330163$, \\
& $17,7),(0.168592226113708,8,10),(0.168319549252442,13,7),(0.167826280904$, \\
& $7,20),(0.167504953109114,11,20),(0.167322600861131,2,10)$, \\
& $(0.167247572766832,8,1)\}$ \\
& 0.167248 \\
&
\end{tabular}

standards for PRS operations (BRC13), lack of awareness and expertise towards BCT adoption (BRC17), privacy challenges with BCT (BRC19) and lack of governance and standards (BRC20) are identified as most influential BRCs. The impact relationship map reflects the relations among BRCs for PRS which is presented in Fig. 3.

\subsection{Correlations among the BRCs}

The different $(\mathrm{D}+\mathrm{R})$ values reflected in Table 10 represent the impact of BRCs. The higher the value, the stronger the participation of that $\mathrm{BRC}$ is to obstruct the implementation of PRS. The BRCs can be arranged as BRC13, BRC1, BRC10, BRC20, BRC8, BRC7, BRC9, BRC2, BRC17, BRC11, BRC12, BRC6, BRC19, BRC18, BRC14, BRC15, BRC5, $\mathrm{BRC} 4, \mathrm{BRC} 16$, and BRC3. In the present study, it was perceived that each BRC is directly persuaded by other BRCs. Inadequate standards for PRS operations (BRC13) determined the highest correlation with other BRCs. Effective PRS implementation requires monitoring, sustaining, and enhancing internal and collaborative processes (Dwivedi et al., 2020). If the effective implementation of the processes is not performed, there will be a significant loss concerning labor and services. In PRS, the transformations in a PRS require financial investments and human resources. Therefore, there is a requirement for a set of standards for PRS operations. By way of contrast, lack of customer cognizance towards PRS and BCT $(B R C 3)$ is the least correlated with other BRCs. In the era of digitalization, consumers search for the implementation of advanced technologies in supply chains (Wang et al., 2019). There is a lack of awareness and knowledge among the consumers in the context of BCT and PRS. 


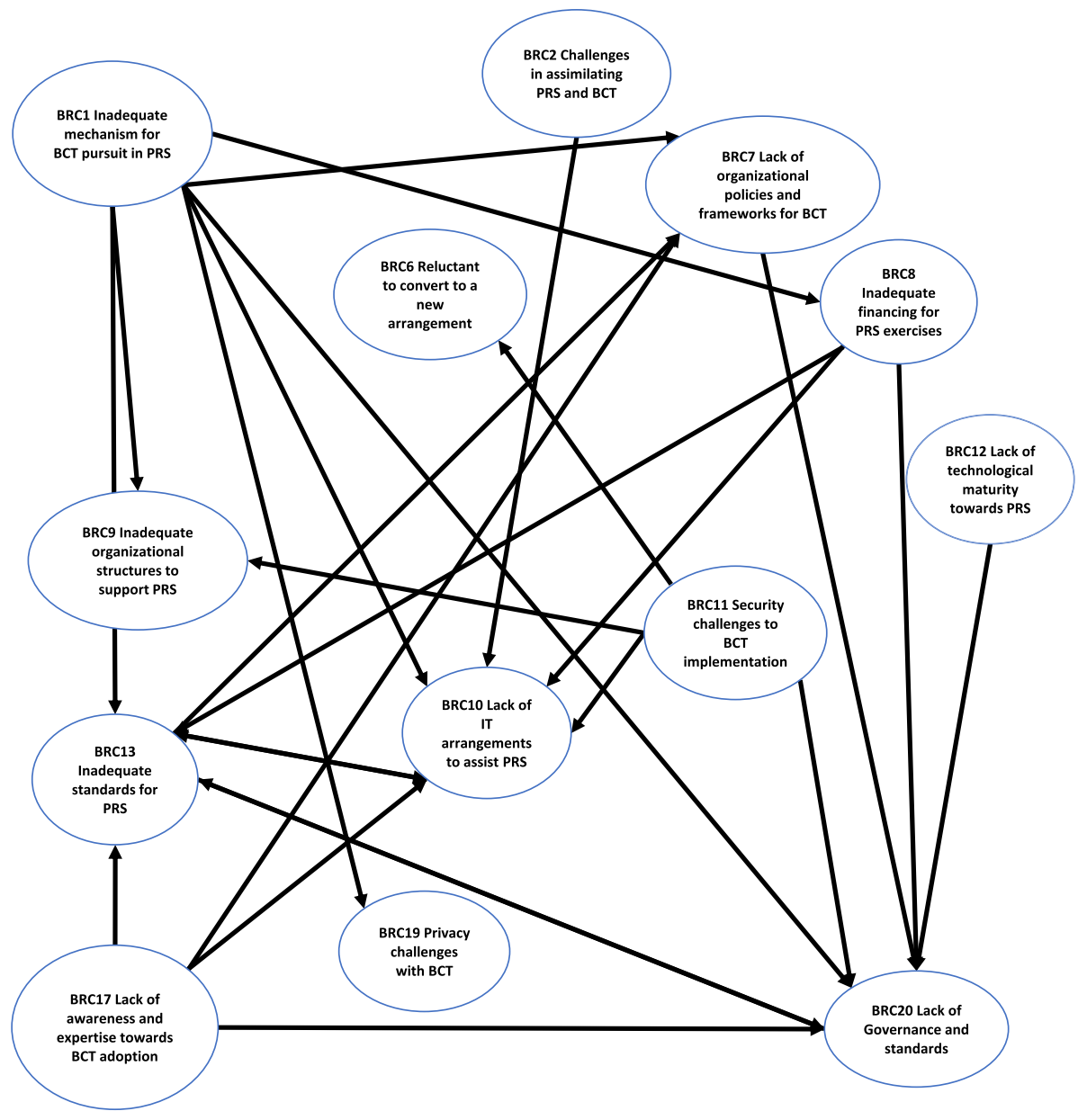

Fig. 3 Impact-relations map for BRC to PRS

This brings the requirement for effective educational programs, conferences, and workshops to make the customer aware of the benefits of BCT adoption. Therefore, effective assessment measures based on BCT adoption will assist the manufacturing industries to remain updated with the latest technologies.

\section{Managerial and practical implications}

This study presents some managerial and practical implications. From the results, causal BRCs for BCT adoption in PRS have been explored. The development of BRCs can be affected by the causal group. Measures should be suggested to improve the causal BRCs for BCT adoption in PRS. This study is beneficial for manufacturing organizations concerned with implementing BCT in PRS by eliminating potential BRCs through organized methods 
in the post-COVID-19 era (Chowdhury et al., 2021). Further, several valuable implications are recommended to managers in the manufacturing industry based on the research findings:

Implication 1: In this study, lack of awareness and expertise towards BCT adoption is reflected as one of the important barriers in the list of BRCs. A higher level of awareness and expertise is essential for adopting BCT in PRS, resulting in efficient execution of PRS in the post-COVID-19 era. Industry managers should ensure that the economic advantages are achieved in their organization with the execution of BCT practices. Further, managers are suggested to learn from the expertise of other organizations executing such practices.

Implication 2: This study's findings reflect that security challenges to BCT implementation is an essential barrier for the implementation of BCT in PRS. The blockchain works on the concept of decentralization that structures data into blocks with multiple transaction settings. Although BCT can provide an error-free set of transactions, there are possibilities of security issues. Manufacturing organizations are reluctant to adopt BCT practices because of security concerns.

Implication 3: Challenges in assimilating BCT and PRS is an important BRC for BCT adoption in PRS. Manufacturing industries are not conscious of the regulations and policies specific to BCT adoption in PRS, resulting in inconvenience in implementing the policies and integrating BCT and PRS.

Implication 4: The high costs linked with BCT implementation is another significant barrier. Most manufacturing organizations are reluctant to invest money and resources to adopt BCT in PRS. Industry managers are encouraged to feature the advantages and economic benefits of BCT adoption in PRS.

The findings of this study can help industry managers in successfully implementing BCT practices for BCT adoption by eliminating BRCs. This study has analyzed BRCs for PRS implementation and examined the ranking and nature of these BRCs. The ranking of the cause-and-effect BRCs can assist decision-makers in advancing strategic policies during PRS implementation in the post-COVID-era. Managers can consider this study as a benchmark for enhancing the manufacturing industry by adopting BCT in PRS.

\section{Conclusions and future research directions}

BCT, which primarily encouraged the Bitcoin cryptocurrency, is a tamper-resistant distributed ledger that might eradicate business frictions hindering innovation adoption (Gausdal et al., 2018). Most industries are confined to traditional methods. BCT is a recent research domain and is unknown to most industries. These industries are not organized to attain the advantages obtainable via BCT adoption. Therefore, it becomes crucial to identify the BRCs through the implementation of PRS in the manufacturing industry. 
In this study, twenty BRCs for PRS implementation were identified through a literature review and expert recommendations. Further, the fuzzy DEMATEL methodology, which considers uncertainty, was adopted to assess the identified BRCs. In the present study, the fuzzy DEMATEL methodology was used to transform qualitative information into quantitative evaluations and identify the most significant BRCs under the cause-and-effect groups that obstruct PRS's execution. The significance of each influencing BRC on PRS's implementation has been effectively identified. Further, the causal interaction among each BRC has been produced through an organized framework. The findings from the study reflect that there are eight BRCs in the cause group and 12 BRCs in the effect group. In the present study, lack of awareness and expertise towards BCT adoption (BRC17) and security challenges to $B C T$ implementation (BRC11) appeared as the most influential BRCs in this group. This reflects that other BRCs can easily influence these BRCs. The results from this study can assist the organizations in making strategic decisions when shifting from a traditional system to PRS.

In emerging economies, manufacturing industries are reluctant to adopt digital technologies. There can be various reasons concerning the lack of information for such reluctance, including high investments and improper infrastructure. Therefore, requirements for adopting BCT in PRS have become essential. To the best of our understanding, there is no pre-existing study that has evaluated the BRCs for PRS in the context of the manufacturing industry. The present study contributes in three main ways. First, the study helps organizations generate cognizance of the essential BRCs for PRS implementation. Second, the study identifies the interactions between the BRCs for PRS adoption and assembles the BRCs into cause-andeffect groups. Third, the study identifies an impact relationship map for the potential BRCs for PRS by adopting an MMDE approach. The main contribution of this study to the present literature is to suggest a framework that industry managers could employ to address the BRCs and advance suitable measures to cater to them for the successful implementation of BCT practices in PRS.

There are a few limitations to this study. The present study adopts BCT that has the potential for enhancing the PRSs in the post-COVID-19 era. The study identifies a list of important BRCs to PRS and recommends measures to cater to them for the successful implementation of BCT in manufacturing industries. In the present study, the number of partaking experts is acceptable in comparison to the current literature. However, more experts can be included in the survey to confirm the exactness of the results. Further, experts considered in this study are from a particular country. In the future, studies could be performed by selecting experts from multiple developed and developing countries to generalize the results. In future studies, other MCDM techniques such as fuzzy ANP, fuzzy BWM, and TISM can also be implemented to evaluate the potential BRCs in PRS and to compare the findings. 


\section{Appendix 1}

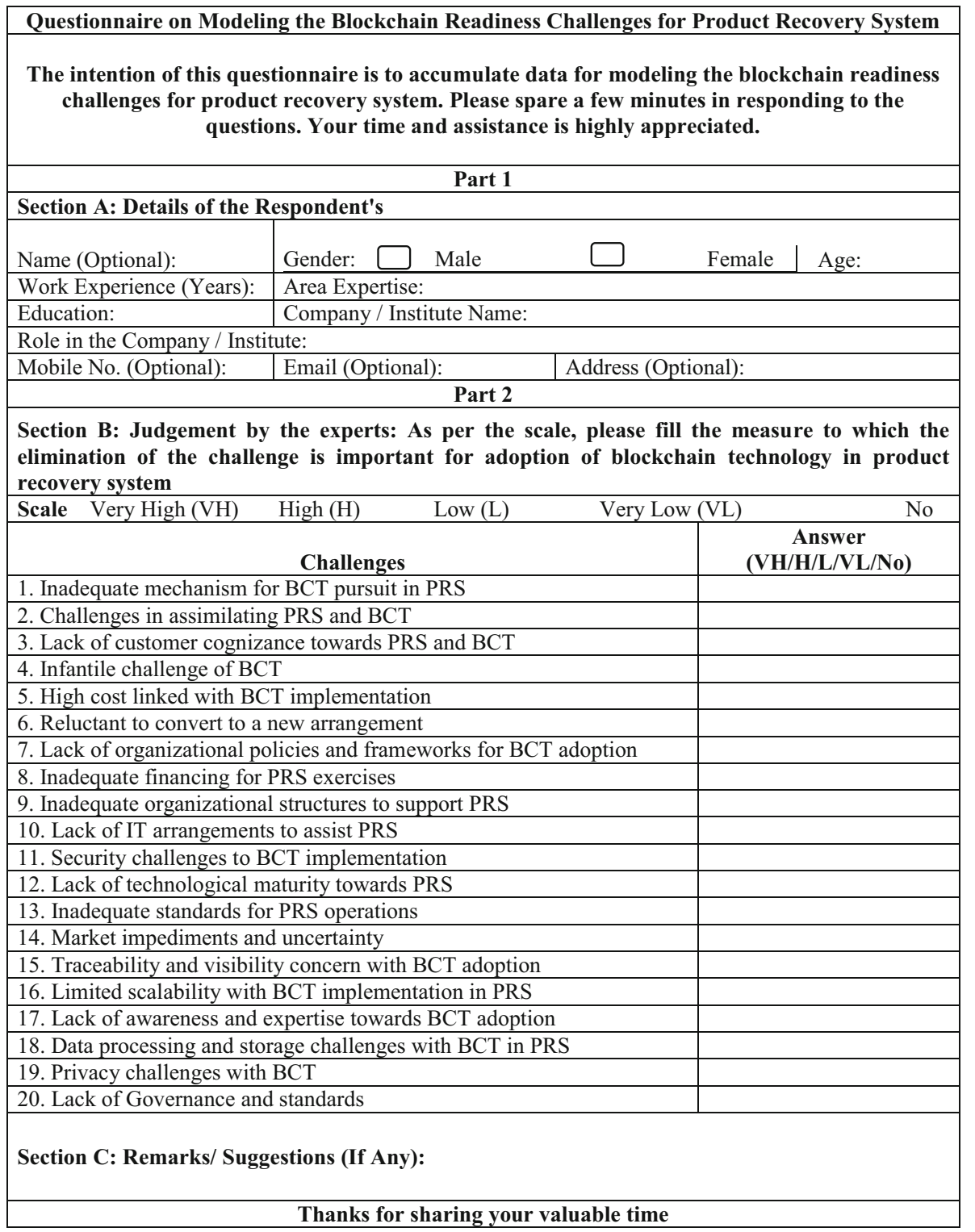




\section{References}

Akter, S., Michael, K., Uddin, M. R., McCarthy, G., \& Rahman, M. (2020). Transforming business using digital innovations: The application of AI, blockchain, cloud and data analytics. Annals of Operations Research, 1-33.

AlZaabi, S., Al Dhaheri, N., \& Diabat, A. (2013). Analysis of interaction between the barriers for the implementation of sustainable supply chain management. The International Journal of Advanced Manufacturing Technology, 68(1-4), 895-905.

Alqahtani, A. Y., Gupta, S. M., \& Nakashima, K. (2019). Warranty and maintenance analysis of sensor embedded products using internet of things in industry 4.0. International Journal of Production Economics, 208, 483-499.

Bag, S., Viktorovich, D. A., Sahu, A. K., \& Sahu, A. K. (2020). Barriers to adoption of blockchain technology in green supply chain management. Journal of Global Operations and Strategic Sourcing, 14(1), 104-133.

Bai, C., \& Sarkis, J. (2020). A supply chain transparency and sustainability technology appraisal model for blockchain technology. International Journal of Production Research, 58(7), 2142-2162.

Balasubramanian, S., Shukla, V., Sethi, J. S., Islam, N., \& Saloum, R. (2021). A readiness assessment framework for Blockchain adoption: A healthcare case study. Technological Forecasting and Social Change, $165,120536$.

Bekrar, A., El Cadi, A. A., Todosijevic, R., \& Sarkis, J. (2021). Digitalizing the closing-of-the-loop for supply chains: A transportation and blockchain perspective. Sustainability, 13(5), 2895.

Biswas, S., Sharif, K., Li, F., Nour, B., \& Wang, Y. (2018). A scalable blockchain framework for secure transactions in IoT. IEEE Internet of Things Journal, 6(3), 4650-4659.

Caldarelli, G., Rossignoli, C., \& Zardini, A. (2020). Overcoming the blockchain oracle problem in the traceability of non-fungible products. Sustainability, 12(6), 2391.

Cannella, S., Bruccoleri, M., \& Framinan, J. M. (2016). Closed-loop supply chains: What reverse logistics factors influence performance? International Journal of Production Economics, 175, 35-49.

Choi, D., Chung, C. Y., Seyha, T., \& Young, J. (2020). Factors affecting organizations' resistance to the adoption of blockchain technology in supply networks. Sustainability, 12(21), 8882.

Chowdhury, P., Paul, S. K., Kaisar, S., \& Moktadir, M. A. (2021). COVID-19 pandemic related supply chain studies: A systematic review. Transportation Research Part E: Logistics and Transportation Review, 148, 102271.

Clohessy, T., \& Acton, T. (2019). Investigating the influence of organizational factors on blockchain adoption: An innovation theory perspective. Industrial Management \& Data Systems., 119(7), 1457-1491.

Dasaklis, T. K., Casino, F., \& Patsakis, C. (2020). A traceability and auditing framework for electronic equipment reverse logistics based on Blockchain: the case of mobile phones. In 2020 11th International Conference on Information, Intelligence, Systems and Applications (pp. 1-7).

de Oliveira, C. T., Luna, M. M., \& Campos, L. M. (2019). Understanding the Brazilian expanded polystyrene supply chain and its reverse logistics towards circular economy. Journal of Cleaner Production, 235 , $562-573$.

Dindarian, A., \& Chakravarthy, S. (2019). Traceability of electronic waste using blockchain technology. Issues in Environmental Science and Technology; Royal Society of Chemistry (RSC): London, UK (pp. 188-212).

Dinh, T. T. A., Liu, R., Zhang, M., Chen, G., Ooi, B. C., \& Wang, J. (2018). Untangling blockchain: A data processing view of blockchain systems. IEEE Transactions on Knowledge and Data Engineering, 30(7), 1366-1385.

Dwivedi, A., \& Madaan, J. (2020). A hybrid approach for modeling the key performance indicators of information facilitated product recovery system. Journal of Modelling in Management., 15(3), 933-965.

Dwivedi, A., Agrawal, D., \& Madaan, J. (2020). Identification and prioritization of issues to implementation of information-facilitated product recovery system for a circular economy. Modern Supply Chain Research and Applications., 2(4), 247-280.

Dwivedi, A., Agrawal, D., Jha, A., Gastaldi, M., Paul, S. K., \& D’Adamo, I. (2021a). Addressing the challenges to sustainable initiatives in value chain flexibility: Implications for sustainable development Goals. Global Journal of Flexible Systems Management, 1-19.

Dwivedi, A., Moktadir, M. A., Jabbour, C. J. C., \& de Carvalho, D. E. (2021b). Integrating the circular economy and industry 4.0 for sustainable development: Implications for responsible footwear production in a big data-driven world. Technological Forecasting and Social Change, 121335.

Ebinger, F., \& Omondi, B. (2020). Leveraging digital approaches for transparency in sustainable supply chains: A conceptual paper. Sustainability, 12(15), 6129.

Esmaeilian, B., Sarkis, J., Lewis, K., \& Behdad, S. (2020). Blockchain for the future of sustainable supply chain management in Industry 4.0. Resources, Conservation and Recycling, 163, 105064. 
Farooq, S., \& O'Brien, C. (2012). A technology selection framework for integrating manufacturing within a supply chain. International Journal of Production Research, 50(11), 2987-3010.

Farooque, M., Jain, V., Zhang, A., \& Li, Z. (2020). Fuzzy DEMATEL analysis of barriers to Blockchain-based life cycle assessment in China. Computers \& Industrial Engineering, 147, 106684.

Fawcett, S. E., Ogden, J. A., Magnan, G. M., \& Cooper, M. B. (2006). Organizational commitment and governance for supply chain success. International Journal of Physical Distribution \& Logistics Management., 36(1), 22-35.

Feng, Q., He, D., Zeadally, S., Khan, M. K., \& Kumar, N. (2019). A survey on privacy protection in blockchain system. Journal of Network and Computer Applications, 126, 45-58.

Fortuna, L. M., \& Diyamandoglu, V. (2017). Optimization of greenhouse gas emissions in second-hand consumer product recovery through reuse platforms. Waste Management, 66, 178-189.

Gausdal, A. H., Czachorowski, K. V., \& Solesvik, M. Z. (2018). Applying blockchain technology: Evidence from Norwegian companies. Sustainability, 10(6), 1985.

Gautam, P., Khanna, A., \& Jaggi, C. K. (2021). An integrated green supply chain model with product recovery management towards a cleaner system. Journal of Cleaner Production, 320, 128850.

Heiss, J., Eberhardt, J., \& Tai, S. (2019). From oracles to trustworthy data on-chaining systems. In 2019 IEEE International Conference on Blockchain (Blockchain) (pp. 496-503). IEEE.

Ho, C. F., Tai, Y. M., Tai, Y. M., \& Chi, Y. P. (2005). A structural approach to measuring uncertainty in supply chains. International Journal of Electronic Commerce, 9(3), 91-114.

Hungud, V., \& Arunachalam, S. K. (2020). Digital twin: Empowering edge devices to be intelligent. Advances in Computers, 117(1), 107-127.

Ivanov, D., Dolgui, A., \& Sokolov, B. (2019). The impact of digital technology and Industry 4.0 on the ripple effect and supply chain risk analytics. International Journal of Production Research, 57(3), 829-846.

Jabbour, C. J. C., Fiorini, P. D. C., Ndubisi, N. O., Queiroz, M. M., \& Piato, É. L. (2020). Digitally-enabled sustainable supply chains in the 21st century: A review and a research agenda. Science of the Total Environment, 725, 138177.

Jain, G., Singh, H., Chaturvedi, K. R., \& Rakesh, S. (2020). Blockchain in logistics industry: In fizz customer trust or not. Journal of Enterprise Information Management., 33(3), 541-558.

Jayaraman, V., Ross, A. D., \& Agarwal, A. (2008). Role of information technology and collaboration in reverse logistics supply chains. International Journal of Logistics: Research and Applications, 11(6), 409-425.

Kamble, S. S., Gunasekaran, A., Subramanian, N., Ghadge, A., Belhadi, A., \& Venkatesh, M. (2021). Blockchain technology's impact on supply chain integration and sustainable supply chain performance: Evidence from the automotive industry. Annals of Operations Research, 1-26.

Kamble, S., Gunasekaran, A., \& Arha, H. (2019). Understanding the Blockchain technology adoption in supply chains-Indian context. International Journal of Production Research, 57(7), 2009-2033.

Karuppiah, K., Sankaranarayanan, B., \& Ali, S. M. (2021). A decision-aid model for evaluating challenges to blockchain adoption in supply chains. International Journal of Logistics Research and Applications, $1-22$.

Katsaliaki, K., Galetsi, P., \& Kumar, S. (2021). Supply chain disruptions and resilience: A major review and future research agenda. Annals of Operations Research, 1-38.

Kazancoglu, Y., Kazancoglu, I., \& Sagnak, M. (2018). Fuzzy DEMATEL-based green supply chain management performance: Application in cement industry. Industrial Management \& Data Systems, 118(2), 412-431.

Khan, F. A., Asif, M., Ahmad, A., Alharbi, M., \& Aljuaid, H. (2020). Blockchain technology, improvement suggestions, security challenges on smart grid and its application in healthcare for sustainable development. Sustainable Cities and Society, 55, 102018.

Khan, S., Khan, M. I., \& Haleem, A. (2019). Evaluation of barriers in the adoption of halal certification: A fuzzy DEMATEL approach. Journal of Modelling in Management, 14(1), 153-174.

Kharlamov, A., \& Parry, G. (2018). Advanced supply chains: Visibility, Blockchain and human behaviour. Innovation and supply chain management (pp. 321-343). Springer.

Khatoon, A., Verma, P., Southernwood, J., Massey, B., \& Corcoran, P. (2019). Blockchain in energy efficiency: Potential applications and benefits. Energies, 12(17), 3317.

Koc, T., \& Bozdag, E. (2017). Measuring the degree of novelty of innovation based on Porter's value chain approach. European Journal of Operational Research, 257(2), 559-567.

Kouhizadeh, M., Saberi, S., \& Sarkis, J. (2021). Blockchain technology and the sustainable supply chain: Theoretically exploring adoption barriers. International Journal of Production Economics, 231, 107831.

Kouhizadeh, M., \& Sarkis, J. (2018). Blockchain practices, potentials, and perspectives in greening supply chains. Sustainability, 10(10), 3652. 
Lampón, J. F., Pérez-Elizundia, G., \& Delgado-Guzmán, J. A. (2021). Relevance of the cooperation in financing the automobile industry's supply chain: The case of reverse factoring. Journal of Manufacturing Technology Management., 32(5), 1094-1112.

Lee, J. H., \& Pilkington, M. (2017). How the blockchain revolution will reshape the consumer electronics industry [future directions]. IEEE Consumer Electronics Magazine, 6(3), 19-23.

Leng, F. L., \& Zailani, S. (2012). Effects of information, material and financial flows on supply chain performance: A study of manufacturing companies in Malaysia. International Journal of Management, 29(1), $293-313$.

Li, C. W., \& Tzeng, G. H. (2009). Identification of a threshold value for the DEMATEL method using the maximum mean de-entropy algorithm to find critical services provided by a semiconductor intellectual property mall. Expert Systems with Applications, 36, 9891-9898.

Liu, X., Wu, H., Wu, W., Fu, Y., \& Huang, G. Q. (2021). Blockchain-enabled ESG reporting framework for sustainable supply chain. Sustainable design and manufacturing 2020 (pp. 403-413). Springer.

Lopes, D. P., Rita, P., \& Treiblmaier, H. (2021). The impact of Blockchain on the aviation industry: Findings from a qualitative study. Research in Transportation Business \& Management, 100669.

Lu, Y. (2019). The blockchain: State-of-the-art and research challenges. Journal of Industrial Information Integration, 15, 80-90.

Luo, S., \& Choi, T. M. (2021). Great partners: How deep learning and blockchain help improve business operations together. Annals of Operations Research, 1-26.

Majeed, A. A., \& Rupasinghe, T. D. (2017). Internet of things (IoT) embedded future supply chains for industry 4.0: An assessment from an ERP-based fashion apparel and footwear industry. International Journal of Supply Chain Management, 6(1), 25-40.

Mangla, S. K., Luthra, S., Mishra, N., Singh, A., Rana, N. P., Dora, M., \& Dwivedi, Y. (2018). Barriers to effective circular supply chain management in a developing country context. Production Planning \& Control, 29(6), 551-569.

Manupati, V. K., Schoenherr, T., Ramkumar, M., Wagner, S. M., Pabba, S. K., \& Inder Raj Singh, R. (2020). A blockchain-based approach for a multi-echelon sustainable supply chain. International Journal of Production Research, 58(7), 2222-2241.

Marconi, M., Marilungo, E., Papetti, A., \& Germani, M. (2017). Traceability as a means to investigate supply chain sustainability: The real case of a leather shoe supply chain. International Journal of Production Research, 55(22), 6638-6652.

Marshall, S. E., \& Archibald, T. W. (2018). Lot-sizing for a product recovery system with quality-dependent recovery channels. Computers \& Industrial Engineering, 123, 134-147.

Mazlan, A. A., Daud, S. M., Sam, S. M., Abas, H., Rasid, S. Z. A., \& Yusof, M. F. (2020). Scalability challenges in healthcare blockchain system-a systematic review. IEEE Access, 8, 23663-23673.

Mohanta, B. K., Jena, D., Panda, S. S., \& Sobhanayak, S. (2019). Blockchain technology: A survey on applications and security privacy challenges. Internet of Things, 8, 100107.

Mubarik, M., Rasi, R. M., \& Faraz, M. (2020). Fostering supply chain integration through blockchain technology: A study of Malaysian manufacturing sector. International Journal of Management, 9(3), 135-147.

Nandi, S., Sarkis, J., Hervani, A. A., \& Helms, M. M. (2021). Redesigning supply chains using blockchainenabled circular economy and COVID-19 experiences. Sustainable Production and Consumption, 27, $10-22$.

Nayak, G., \& Dhaigude, A. S. (2019). A conceptual model of sustainable supply chain management in small and medium enterprises using blockchain technology. Cogent Economics \& Finance, 7(1), 1667184.

O'Dair, M., \& Beaven, Z. (2017). The networked record industry: How blockchain technology could transform the record industry. Strategic Change, 26(5), 471-480.

Opricovic, S., \& Tzeng, G. H. (2003). Defuzzification within a multicriteria decision model. International Journal of Uncertainty, Fuzziness and Knowledge-Based Systems, 11(05), 635-652.

Paliwal, V., Chandra, S., \& Sharma, S. (2020). Blockchain technology for sustainable supply chain management: A systematic literature review and a classification framework. Sustainability, 12(18), 7638.

Pan, J., Tao, Y., Lee, L. H., \& Chew, E. P. (2015). Production planning and inventory control for a two-product recovery system. IIE Transactions, 47(12), 1342-1362.

Parmar, P. S., \& Desai, T. N. (2020). Evaluating sustainable lean six sigma enablers using fuzzy DEMATEL: A case of an Indian manufacturing organization. Journal of Cleaner Production, 265, 121802.

Parung, J. (2019). The use of Blockchain to support sustainable supply chain strategy. In IOP Conference Series: Materials Science and Engineering, vol 703, no 1 (p. 012001).

Patil, A., Shardeo, V., Dwivedi, A., \& Madaan, J. (2020). An integrated approach to model the blockchain implementation barriers in humanitarian supply chain. Journal of Global Operations and Strategic Sourcing, 14(1), 81-103. 
Pilkington, M. (2016). Blockchain technology: Principles and applications. In Research handbook on digital transformations. Edward Elgar Publishing.

Pratap, S., Daultani, Y., Dwivedi, A. and Zhou, F. (2021). Supplier selection and evaluation in e-commerce enterprises: A data envelopment analysis approach, Benchmarking: An International Journal, 1-17.

Prewett, K. W., Prescott, G. L., \& Phillips, K. (2020). Blockchain adoption is inevitable-Barriers and risks remain. Journal of Corporate Accounting \& Finance, 31(2), 21-28.

Rana, N. P., Dwivedi, Y. K., \& Hughes, D. L. (2021). Analysis of challenges for blockchain adoption within the Indian public sector: an interpretive structural modelling approach. Information Technology \& People, $1-29$.

Rane, S. B., \& Narvel, Y. A. (2019). Re-designing the business organization using disruptive innovations based on blockchain-IoT integrated architecture for improving agility in future Industry 4.0. Benchmarking: an International Journal, 8(5), 1883-1908.

Rejeb, A., \& Rejeb, K. (2020). Blockchain and supply chain sustainability. Logforum, 16(3), 363-372.

Rezaee, M. (2019). Opportunities of blockchain technologies in closed-loop supply chain management. Master of Science Thesis, POLITECNICO DI MILANO, Italy.

Richter, B., Mengelkamp, E., \& Weinhardt, C. (2018). Maturity of blockchain technology in local electricity markets. In 2018 15th International Conference on the European Energy Market (pp. 1-6).

Rogerson, M., \& Parry, G. C. (2020). Blockchain: Case studies in food supply chain visibility. Supply Chain Management, 25(5), 601-614.

Saberi, S., Kouhizadeh, M., Sarkis, J., \& Shen, L. (2019). Blockchain technology and its relationships to sustainable supply chain management. International Journal of Production Research, 57(7), 2117-2135.

Sarker, B. R., Chawhan, A. D., \& Biswas, P. (2009). An optimal policy for recovery and procurement under multiple setups. Opsearch, 6(4), 390-417.

Sharma, S. K., Al-Badi, A. H., Govindaluri, S. M., \& Al-Kharusi, M. H. (2016). Predicting motivators of cloud computing adoption: A developing country perspective. Computers in Human Behavior, 62, 61-69.

Shoaib, M., Lim, M. K., \& Wang, C. (2020). An integrated framework to prioritize blockchain-based supply chain success factors. Industrial Management and Data Systems, 120, 2103-2131.

Singh, R., \& Bhanot, N. (2020). An integrated DEMATEL-MMDE-ISM based approach for analysing the barriers of IoT implementation in the manufacturing industry. International Journal of Production Research, 58(8), 2454-2476.

Sundarakani, B., Ajaykumar, A., \& Gunasekaran, A. (2021). Big data driven supply chain design and applications for blockchain: An action research using case study approach. Omega, 102, 102452.

Sunmola, F. T. (2021). Context-aware blockchain-based sustainable supply chain visibility management. Procedia Computer Science, 180, 887-892.

Tian, F. (2016). An agri-food supply chain traceability system for China based on RFID \& blockchain technology. In 2016 13th International Conference on Service Systems and Service Management (pp. 1-6), IEEE.

Tozanli, Ö., Kongar, E., \& Gupta, S. M. (2020). Trade-in-to-upgrade as a marketing strategy in disassemblyto-order systems at the edge of blockchain technology. International Journal of Production Research, 58(23), 7183-7200.

Vafadarnikjoo, A., Ahmadi, H. B., Liou, J. J., Botelho, T., \& Chalvatzis, K. (2021). Analyzing blockchain adoption barriers in manufacturing supply chains by the neutrosophic analytic hierarchy process. Annals of Operations Research, 1-28.

Varriale, V., Cammarano, A., Michelino, F., \& Caputo, M. (2020). The unknown potential of blockchain for sustainable supply chains. Sustainability, 12(22), 9400.

Verhoeven, P., Sinn, F., \& Herden, T. T. (2018). Examples from blockchain implementations in logistics and supply chain management: Exploring the mindful use of a new technology. Logistics, 2(3), 20.

Viriyasitavat, W., \& Hoonsopon, D. (2019). Blockchain characteristics and consensus in modern business processes. Journal of Industrial Information Integration, 13, 32-39.

Wang, Y., Han, J. H., \& Beynon-Davies, P. (2019). Understanding blockchain technology for future supply chains: A systematic literature review and research agenda. Supply Chain Management, 24(1), 62-84.

Wen, Z., Liao, H., \& Emrouznejad, A. (2021). Information representation of blockchain technology: Risk evaluation of investment by personalized quantifier with cubic spline interpolation. Information Processing \& Management, 58(4), 102571.

Yadav, S., \& Singh, S. P. (2020). Blockchain critical success factors for sustainable supply chain. Resources, Conservation and Recycling, 152, 104505.

Yadav, V. S., Singh, A. R., Raut, R. D., \& Govindarajan, U. H. (2020). Blockchain technology adoption barriers in the Indian agricultural supply chain: An integrated approach. Resources, Conservation and Recycling, $161,104877$. 
Ye, C., Cao, W., \& Chen, S. (2020). Security challenges of blockchain in Internet of things: Systematic literature review. Transactions on Emerging Telecommunications Technologies, e4177.

Zachariadis, M., Hileman, G., \& Scott, S. V. (2019). Governance and control in distributed ledgers: Understanding the challenges facing blockchain technology in financial services. Information and Organization, 29(2), 105-117.

Zhang, A., Zhong, R. Y., Farooque, M., Kang, K., \& Venkatesh, V. G. (2020). Blockchain-based life cycle assessment: An implementation framework and system architecture. Resources, Conservation and Recycling, 152, 104512.

Zheng, K., Zhang, Z., \& Gauthier, J. (2020). Blockchain-based intelligent contract for factoring business in supply chains. Annals of Operations Research, 1-21.

Zwitter, A., \& Hazenberg, J. (2020). Decentralized network governance: Blockchain technology and the future of regulation. Frontiers in Blockchain, 3, 12.

Publisher's Note Springer Nature remains neutral with regard to jurisdictional claims in published maps and institutional affiliations. 